\title{
Geologic and geodetic constraints on the seismic hazard of Malawi's active faults: The Malawi Seismogenic Source Database (MSSD)
}

Jack N. Williams ${ }^{1,2 *}$, Luke N. J. Wedmore ${ }^{2}$, Åke Fagereng ${ }^{1}$, Maximilian J. Werner ${ }^{2}$, Hassan Mdala ${ }^{3}$, Donna J Shillington ${ }^{4}$, Christopher A Scholz ${ }^{5}$, Folarin Kolawole ${ }^{6}$, Lachlan J. M. Wright ${ }^{5}$, Juliet Biggs ${ }^{2}$, 5 Zuze Dulanya ${ }^{7}$, Felix Mphepo $^{3}$, Patrick Chindandali ${ }^{8}$

${ }^{1}$ School of Environmental Sciences, Cardiff University, Cardiff, UK

${ }^{2}$ School of Earth Sciences, University of Bristol, Bristol, UK

${ }^{3}$ Geological Survey Department, Mzuzu Regional Office, Mzuzu, Malawi

$10{ }^{4}$ School of Earth and Sustainability, Northern Arizona University, Flagstaff, Arizona, USA

${ }^{5}$ Department of Earth Sciences, Syracuse University, Syracuse, New York, USA

${ }^{6}$ BP America, Houston, Texas, U.S.

${ }^{7}$ Geography and Earth Sciences Department, University of Malawi, Zomba, Malawi

${ }^{8}$ Geological Survey Department, Zomba, Malawi

15 *now at the Department of Geology, University of Otago, Dunedin, New Zealand

Correspondence to: Jack N. Williams (jack.williams@otago.ac.nz)

Abstract. Active fault data are commonly used in seismic hazard assessments, but there are challenges in deriving the slip rate, geometry, and frequency of earthquakes along active faults. Herein, we present the open-access geospatial Malawi Seismogenic Source Database (MSSD), which describes the seismogenic properties of faults that have formed during East

20 African rifting in Malawi. We first use empirical observations to geometrically classify active faults into section, fault, and multi-fault seismogenic sources. For sources in the North Basin of Lake Malawi, slip rates can be derived from the vertical offset of a seismic reflector that is estimated to be $75 \mathrm{ka}$ based on dated core. Elsewhere, slip rates are constrained from advancing a 'systems-based' approach that partitions geodetically-derived rift extension rates in Malawi between seismogenic sources using a priori constraints on regional strain distribution in magma-poor continental rifts. Slip rates are then combined with source geometry and empirical scaling relationships to estimate earthquake magnitudes and recurrence intervals, and their uncertainty is described from the variability of outcomes from a logic tree used in these calculations. We find that for sources in the Lake Malawi's North Basin, where slip rates can be derived from both the geodetic data and the offset seismic reflector, the slip rate estimates are within error of each other, although those from the offset reflector are higher. Sources in the MSSD are 5-200 km long, which implies that large magnitude ( $\left.\mathrm{M}_{\mathrm{W}} 7-8\right)$ earthquakes may occur in

30 Malawi. Low slip rates $(0.05-2 \mathrm{~mm} / \mathrm{yr})$, however, mean that the frequency of such events will be low (recurrence intervals $\sim 10^{3}-10^{4}$ years). The MSSD represents an important resource for investigating Malawi's increasing seismic risks and provides a framework for incorporating active fault data into seismic hazard assessment in other tectonically active regions. 


\section{Introduction}

Earthquake hazards are most frequently quantified as the probability of exceeding a specific ground motion intensity in a

35 given time period through probabilistic seismic hazard analysis (PSHA; e.g., Cornell, 1968; Gerstenberger et al., 2020; McGuire, 1995). The main components of a PSHA are seismogenic sources, which cumulatively describe the magnitude and frequency of earthquakes within the assessed region, and a ground motion model, which describes the ground motion intensities earthquakes will induce. Typically, seismogenic sources were developed by considering the historical and instrumental records of earthquakes, however: (1) the relatively short duration of these records imply they are not necessarily representative of a region's long term seismicity (e.g., Hodge et al., 2015; Stein et al., 2012), and (2) it is often unclear how this record should be used to parameterize a seismogenic source's spatial extent (Helmstetter and Werner, 2012) and maximum expected earthquake magnitude (Poggi et al., 2017). Therefore, it is now common to also incorporate fault-based seismogenic sources into PSHA, which combine geologic, paleoseismic, and/or geodetic information to describe the magnitude and frequency of earthquakes on known active faults (e.g., Gómez-Novell et al., 2020; Morell et al., 2020; Pace et al., 2016; Pagani et al., 2020; Stirling et al., 2012).

To assess earthquake frequency on active faults, an estimate of the earthquake recurrence interval and/or slip rate on each fault is required (e.g., Molnar, 1979; Wallace, 1970; Youngs and Coppersmith, 1985). Typically, slip rates are derived from: (1) planar or linear geologic features that have been offset by a fault and have a known age (McCalpin, 2009) and/or (2) geodetic measurements of surface interseismic strain accumulation using Global Navigation Satellite Systems, and from which fault slip rates are constrained using 1D velocity profiles (Bendick et al., 2000), 2D block models (Wallace et al., 2012; Zeng and Shen, 2014), or by partitioning regional geodetically measured strain across multiple faults (Cox et al., 2012; Williams et al., 2021b). However, whilst geodetic measurements have been made only over the past few decades, offset geologic markers sample the displacement accrued by a fault over timescales of $10^{2}-10^{5}$ years. This is problematic as earthquakes along a single fault may temporally cluster (Cowie et al., 2012; DuRoss et al., 2020; Wedmore et al., 2017; Weldon et al., 2004), and/or there may be transient variations in the rate of interseismic strain accumulation (Dolan and Meade, 2017; Hetland and Hager, 2006). In either case, this implies that a fault's slip rate will not necessarily be the same when measured at different temporal scales (Beauval et al., 2018; Bormann et al., 2016; Cowie and Roberts, 2001; Fagereng and Biggs, 2019; Litchfield et al., 2014; Petersen et al., 2014; Polonia et al., 2004).

The likely magnitude of an earthquake along an active fault can be inferred from empirically-derived scaling relationships between fault geometry (e.g. length or area) and magnitude (Kanamori and Anderson, 1975; Leonard, 2010; Stirling et al., 2013; Thingbaijam et al., 2017; Wells and Coppersmith, 1994; Wesnousky, 2008). However, faults do not necessarily rupture along their full length in a single event, but may also host shorter ruptures bound by along-strike geometrical complexities, and/or longer 'multi-fault' earthquakes where adjacent faults rupture simultaneously (Biasi and Wesnousky, 
2016, 2017; DuRoss et al., 2016; Fletcher et al., 2014; Litchfield et al., 2018). Furthermore, large magnitude (M> 7) earthquakes can extend across the full width of the crust's seismogenic layer, and in these cases it is unclear how fault area scales with magnitude (Hanks and Bakun, 2002; Leonard, 2010; Shaw, 2013; Shaw and Scholz, 2001). The regional strain rate and tectonic environment from which empirical earthquake scaling data are collated will also influence these relationships (Stirling et al., 2013).

Cumulatively, these challenges mean there is aleatory variability (i.e., the uncertainty related to the stochastic nature of earthquake occurrence) and epistemic uncertainty (i.e., the uncertainty related to limited datasets or knowledge of the earthquake process) when developing fault-based seismogenic sources (Gerstenberger et al., 2020; Marzocchi et al., 2015; Morell et al., 2020). Hence, despite its intuitive premise, questions remains about the extent to which geological fault information improves the skill of probabilistic earthquake forecasts at the timescales (50-100 years) of interest in PSHA (Nicol et al., 2016; Rhoades et al., 2018; Strader et al., 2017; Taroni et al., 2018; Zechar et al., 2013). More pertinently, many regions currently lack the active fault data required to develop fault-based seismogenic sources (Perea et al., 2006; Styron and Pagani, 2020; Williams et al., 2021b).

80

In this study, we present the Malawi Seismogenic Source Database (MSSD), in which we collate the inferred geometry, slip rate, and earthquake magnitude, and recurrence interval of active faults in Malawi, and whose development has required addressing many of the challenges described above. For example, fault slip rates have been previously derived in central and northern Malawi based on the offset of a $75 \mathrm{Ka}$ reflector in seismic reflection surveys in Lake Malawi (Shillington et al.,

85 2020) whilst in southern Malawi, slip rates have been inferred by partitioning geodetically-derived regional extension rates across faults (Williams et al., 2021b). By extending the use of geodetic methods to estimate fault slip rates in Lake Malawi, we can use the MSSD to test whether slip rates derived at timescales from $10^{1}$ to $10^{5}$ years in Malawi can be reconciled. Furthermore, we outline how the observed along-strike segmentation of active faults in Malawi (Accardo et al., 2018; Contreras et al., 2000; Hodge et al., 2018a, 2019; Laõ-Dávila et al., 2015; Macheyeki et al., 2015; Scholz et al., 2020;

90 Shillington et al., 2020; Wedmore et al., 2020b, 2020a), fault intersections at depth (Gaherty et al., 2019; Scholz and Contreras, 1998), and a 30-40 km thick seismogenic layer (Craig and Jackson, 2021; Ebinger et al., 2019; Nyblade and Langston, 1995; Stevens et al., 2021) are incorporated into the MSSD earthquake magnitude estimates. Previous estimates of earthquake recurrence intervals in southern Malawi were constrained only between $10^{2}-10^{5}$ years (Williams et al., 2021b). However, in the MSSD we incorporate a new geodetic model that has smaller uncertainties (Wedmore et al., 2021), and we describe a new probabilistic approach to more rigorously describe recurrence interval and slip rate uncertainties.

Cumulatively, the steps taken to investigate fault geometry, slip rate, and earthquake source properties in the MSSD will be of interest to other regional seismic hazard studies, particularly those with few geologic and geodetic constraints on fault activity. Seismic risk in Malawi, and elsewhere along the East African Rift, is increasing because of rapid population growth 
100 and the proliferation of seismically vulnerable building stock (Delvaux et al., 2017; Giordano et al., 2021; Goda et al., 2016, 2021; Hodge et al., 2015; Ngoma et al., 2019; Novelli et al., 2019). The geospatial, kinematic, and earthquake source data in the MSSD are freely available, and we suggest that the database will be an important resource for seismic hazard planning in the region.

\section{Seismotectonic setting of Malawi}

\subsection{Tectonic setting of Malawi}

A $900-\mathrm{km}$-long section of the East African Rift's (EAR) Western Branch passes through Malawi (Fig. 1). Geodetic models imply that this section of the EAR accommodates 0.5-1.5 mm/yr ENE-WSW extension between the San and Rovuma plates (Fig. 1; Wedmore et al., 2021). In central and northern Malawi, the EAR has been flooded by Lake Malawi, whilst in southern Malawi, the rift floor and associated faults are subaerially exposed (Fig. 1b). South of the Rungwe Volcanic

110 Province in southwestern Tanzania, there is no reported surface volcanism and only minor, if any, melts in its lower crust (Accardo et al., 2020; Hopper et al., 2020; Njinju et al., 2019; Wang et al., 2019). The Malawi section of the EAR is therefore considered to be magma-poor.

A multidisciplinary dataset of 113 fault traces was compiled by Williams et al., (2021a, 2021c) in the Malawi Active Fault

115 Database (MAFD). The MAFD includes 90 basement-involved faults that were mapped from geological maps, high resolution digital elevation models, and 2D seismic reflection surveys (Scholz et al., 2020; Shillington et al., 2020) and that have demonstrably shown evidence of displacement during EAR activity in Malawi. The remaining 23 faults in the MAFD are buried intrarift faults inferred from aeromagnetic (Kolawole et al., 2018a, 2021a) or gravity data (Chisenga et al., 2019), and hence no definitive evidence of displacements associated with East African rifting, but are well-oriented for reactivation

120 in the regional stress field (Dawson et al., 2018; Williams et al., 2019, 2021c). The MAFD contains basic geomorphic and mapping attributes following the format of the Global Earthquake Model Global Active Faults Database (Styron and Pagani, 2020). In keeping with practice elsewhere (Faure Walker et al., 2021; Styron et al., 2020) the MSSD contains data that are considered to be more subjective and may be liable to change (e.g. earthquake recurrence intervals).

\subsection{Seismicity in Malawi}

125 The instrumental record of seismicity in Malawi is complete for events $\mathrm{M}_{\mathrm{w}}>4.5$ from 1965 (Fig. 1; Hodge et al., 2015; Poggi et al., 2017). In this record, the largest event in Malawi is the $1989 \mathrm{M}_{\mathrm{W}} 6.3$ Salima Earthquake with its unusually deep focal depth $(32 \pm 5 \mathrm{~km})$ demonstrative of the region's thick seismogenic layer (Fig. 1b; Jackson and Blenkinsop, 1993). Recent local deployments of seismometers in northern and southern Malawi demonstrate that the base of this seismogenic layer is 


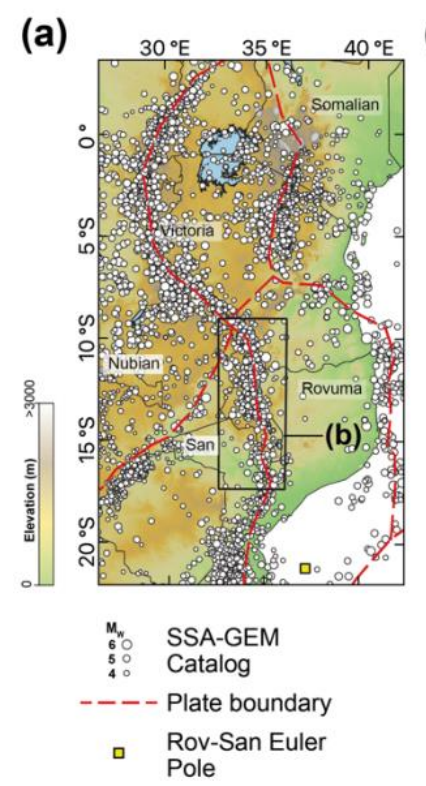

(b)

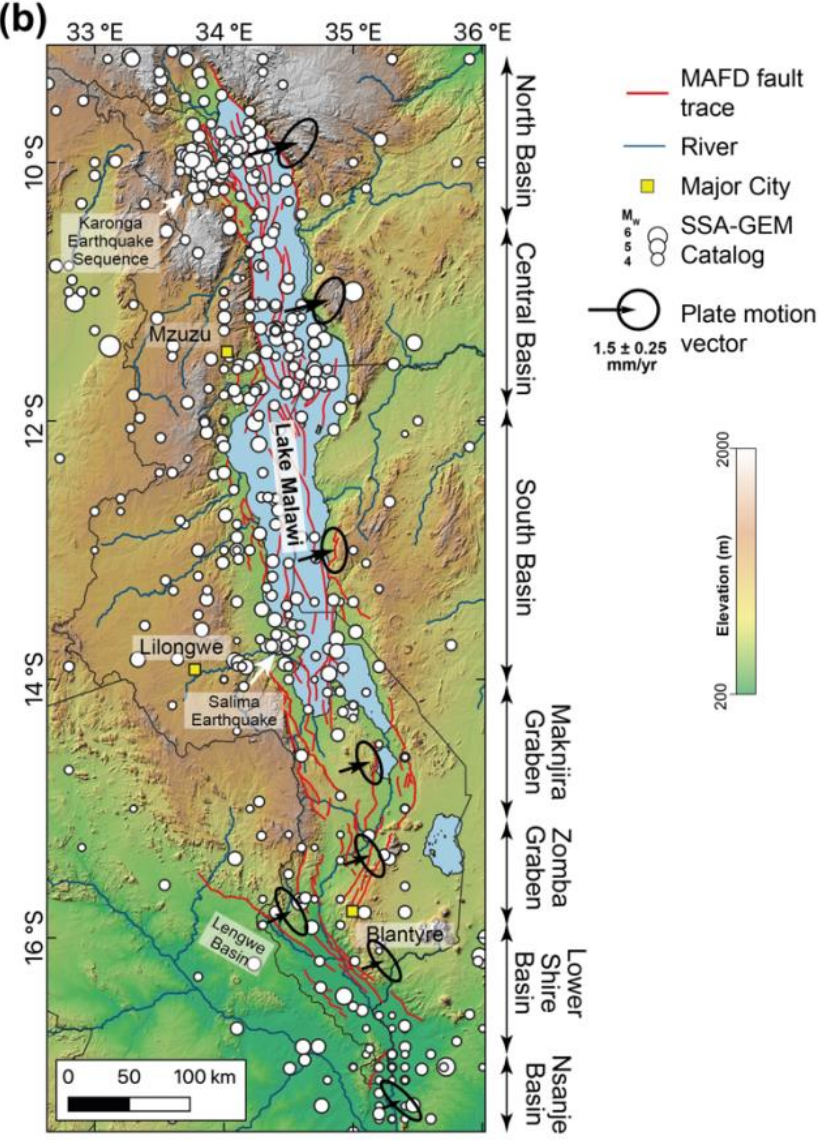

Figure 1: (a) Location of Malawi within the context of an East African Rift scale geodetic model (Wedmore et al., 2021) and earthquake locations from the Sub-Saharan Africa Global Earthquake Model Catalog (SSA-GEM; Poggi et al., 2017). (b) The Malawi Active Fault Database (MAFD) and major EAR basins in Malawi (Williams et al., 2021c). Plate motion vector for central point of each basin for the Rovuma-San Euler pole (Wedmore et al., 2021), with error ellipse modelled using methods described in Robertson et al., (2016). Figures underlain by (a) $90 \mathrm{~m}$ resolution Global 30 Arc-Second Elevation (GTOPO30) Digital Elevation Model and (b) Shuttle Radar Topography Mission 30 m DEM (Sandwell et al., 2011).

approximately coincident with the Moho (35-45 km; Ebinger et al., 2019; Njinju et al., 2019; Stevens et al., 2021; Sun et al., 2021; Wang et al., 2019), however, the data cannot resolve whether the two coincide, if there is an interval of lower aseismic crust, or if seismicity extends into the upper lithospheric mantle. In either case, earthquakes may nucleate throughout the

140 seismogenic layer (Ebinger et al., 2019; Stevens et al., 2021) with evidence for moderate-magnitude, shallow seismicity illustrated by the 2009 Karonga earthquake sequence in northern Malawi (Biggs et al., 2010; Fagereng, 2013). This sequence 
principally consisted of four $\mathrm{M}_{\mathrm{W}}$ 5.5-5.9 events with focal depths $<8 \mathrm{~km}$ (Fig. 1b; Biggs et al., 2010; Gaherty et al., 2019) and resulted in a 9- to $18 \mathrm{~km}$-long surface rupture along the previously unrecognised St Mary fault (Hamiel et al., 2012; Kolawole et al., 2018b; Macheyeki et al., 2015). Focal mechanism stress inversions indicate a normal fault stress state in

145 Malawi with an ENE-WSW trending minimum principal compressive stress ( $\sigma_{3}$; Delvaux and Barth, 2010; Ebinger et al., 2019; Williams et al., 2019).

Although no $\mathrm{M}_{\mathrm{W}}>6.5$ events have been recorded instrumentally in Malawi, steep 10- to 20-m-high and 50- to 130-km-long fault scarps in Malawi imply that $\mathrm{M}_{\mathrm{W}}$ 6.5-7.8 events have occurred in the Late Quaternary (Hodge et al., 2019, 2020; Jackson and Blenkinsop, 1997; Wedmore et al., 2020b, 2020a; Williams et al., 2021b). Furthermore, events of this magnitude have been recorded elsewhere in the EAR Western Branch (Ambraseys, 1991; Ayele and Kulhanek, 2000; Delvaux and Barth, 2010; Fenton and Bommer, 2006; Kervyn et al., 2006; Vittori et al., 1997).

Using the instrumental record of seismicity, PSHA indicates there is a $10 \%$ probability of exceeding (PoE) $\sim 0.15 \mathrm{~g}$ in 50

years in Malawi (Poggi et al., 2017). However, when basic geodetic and geologic data were combined to develop seven fault-based seismogenic sources around Lake Malawi, hazard levels around the fault sources were much higher (10\% PoE $0.25 \mathrm{~g}$ in 50 years), particularly at low probabilities of exceedance and long vibration periods (Hodge et al., 2015). Scenariobased seismic risk assessment indicates that a full $\mathrm{M}_{\mathrm{W}} 7.7$ rupture of the Bilila-Mtakataka fault in southern Malawi would result in 160,000-440,000 collapsed buildings (Goda et al., 2021).

\section{The Malawi Seismogenic Source Database}

The Malawi Seismogenic Source Database (MSSD) is a geospatial database that documents the geometry, slip rate, and seismogenic properties (i.e., earthquake magnitude and frequency) of active faults in Malawi (Fig. 2, Table 1). Each geospatial feature represents a potential earthquake rupture or 'source' and is classified based on its geometry into one of three types: section, fault, or multi-fault. Source types are mutually exclusive, and so if incorporated into a PSHA, they should be assigned relative weightings. The MSSD is comparable to the Database of Individual Seismogenic Sources in Italy (Basili et al., 2008), the Taiwan Earthquake Model (Shyu et al., 2016), or the New Zealand Community Fault Model (Van Dissen et al., 2021). The MSSD is the first seismogenic source database in central and northern Malawi, and represents an update of the South Malawi Seismogenic Source Database (SMSSD; Williams et al., 2021b) because it incorporates new active fault traces (Kolawole et al., 2021a; Williams et al., 2021c), new geodetic data (Wedmore et al., 2021) and a statistical treatment of uncertainty in the logic tree approach (Sect. 3.4).

The MSSD itself consists of two components: (1) a 3D geometrical model of seismogenic sources in Malawi, and (2) the mapped trace of each source, which is associated with the source attributes (Table 1). These are freely available under a Creative Commons CC-BY-4.0 licence on the Zenodo Data Archive (https://zenodo.org/record/5599617\#.YXhT2i0Rpz8) 
175 and on Github (https://github.com/LukeWedmore/malawi_seismogenic_source_database/tree/v1.0). Future iterations will be released on both and so we encourage users to consult these pages for the most up-to-date version.

Table 1: List and brief description of fault geometry, slip rate estimates, and earthquake source attributes in the MSSD. Attributes are assigned to each rupture source, with section, fault, and multi-fault ruptures stored in distinct shapefiles.

\begin{tabular}{|c|c|c|c|}
\hline Attribute & Type & Description & Notes \\
\hline MSSD_id & integer & $\begin{array}{l}\text { Unique numerical reference ID for each } \\
\text { seismic source }\end{array}$ & $\begin{array}{l}\text { ID } 00-300 \text { is section rupture } \\
\text { ID } 300-500 \text { is fault rupture } \\
\text { ID } 600-700 \text { is a multi-fault rupture }\end{array}$ \\
\hline & & & $\begin{array}{l}\text { For sections and faults, the name of the fault (flt_name) } \\
\text { and larger multifault (mflt_name) system they are hosted } \\
\text { on are also given respectively. }\end{array}$ \\
\hline length $\left(L_{s}\right)$ & $\begin{array}{l}\text { real } \\
\text { number }\end{array}$ & $\begin{array}{l}\text { Straight-line distance in } \mathrm{km} \text { between } \\
\text { tips, or sum of } L_{\text {sec }} \text { for segmented faults, } \\
\text { and sum of } L_{\text {fault }} \text { for multi faults }\end{array}$ & $\begin{array}{l}\text { Measured in } \mathrm{km} \text { to } 1 \text { decimal place. Except for linking } \\
\text { sections, must be }>5 \mathrm{~km} \text { (Sect. 3.1.1). }\end{array}$ \\
\hline area & integer & $\begin{array}{l}\text { Calculated from } L_{s} \text { multiplied by Eq. } 1 \\
\text { or based on fault truncation }\end{array}$ & Measured in $\mathrm{km}^{2}$. \\
\hline strike & integer & $\begin{array}{l}\text { Measured from tips, using bearing that } \\
\text { is }<180^{\circ} \text {. }\end{array}$ & Input for slip rate estimates (Eq. 2). \\
\hline dip_dir & string & Compass quadrant that fault dips in. & \\
\hline slip_type & string & Source kinematics & $\begin{array}{l}\text { All sources in the MSSD assumed to be normal } \\
\text { (Williams et al., 2019). }\end{array}$ \\
\hline
\end{tabular}



$\begin{array}{lll}\text { slip_rate } & \begin{array}{l}\text { real } \\ \text { number }\end{array} & \begin{array}{l}\text { Mean value from repeating Eq. (2) in } \\ \text { Monte Carlo simulations. }\end{array}\end{array}$

\begin{abstract}
S_rate_err real $1 \sigma$ error from Monte Carlo slip rate number simulations.

mag_lower real Lower magnitude estimate. Calculated number from Leonard, (2010) scaling relationship (Eq. 4) for $L_{s}$ or $A_{s}$, and using lower estimates of $c_{1}$ and $c_{2}$ constants.
\end{abstract}
mag_med real Mean magnitude estimate. Calculated number from Leonard, (2010) scaling relationship (Eq. 4) for $L_{s}$ or $A_{s}$, and using mean estimates of $c_{l}$ and $c_{2}$ constants.
mag_upper real Upper magnitude estimate. Calculated number from Leonard, (2010) scaling relationship (Eq. 4) for $L_{s}$ or $A_{s}$, and using upper estimates of $c_{1}$ and $c_{2}$ constants.

ri_lower integer Calculated as $1 \sigma$ below the mean value of the Monte Carlo simulations (assuming a log normal distribution).
ri_med integer Mean value from $\log$ of recurrence interval Monte Carlo simulations.
ri_upper integer Calculated as $1 \sigma$ above the mean value of the Monte Carlo simulations (assuming a log normal distribution).

MAFD_id integer ID of equivalent structure in Malawi Active Fault Database (Williams et al., 2021c)
In $\mathrm{mm} / \mathrm{yr}$. All sources in the MSSD assumed to be normal, so is equivalent to dip-slip rate. Reported to two significant figures

Reported to one decimal place

Reported to one decimal place

Reported to one decimal place

Reported to two significant figures.

Reported to two significant figures.

Reported to two significant figures.

Multifault sources will have multiple ID's. 
Geometrical complexities that are $<5 \mathrm{~km}$ long (e.g., relay zone-breaching structures) are interpreted to be 'hard-linking' sections (Peacock et al., 2016), and the insignificant length means they are not considered as distinct sources in the MSSD.

'Fault' seismogenic sources are those that are bounded by the fault tips mapped in the MAFD (Fig. 2). In their compilation 190 of dip-slip surface ruptures, Biasi and Wesnousky, (2017) noted only $10 \%$ of earthquakes exhibited branching ' $\mathrm{Y}$ ' geometries in map view, and the paucity of branching earthquakes is consistent with numerical modelling (Bhat et al., 2007; Geist and Parsons, 2020). Therefore, where we identify fault branches, we consider these as distinct, partially overlapping fault seismogenic sources (Fig. 2).
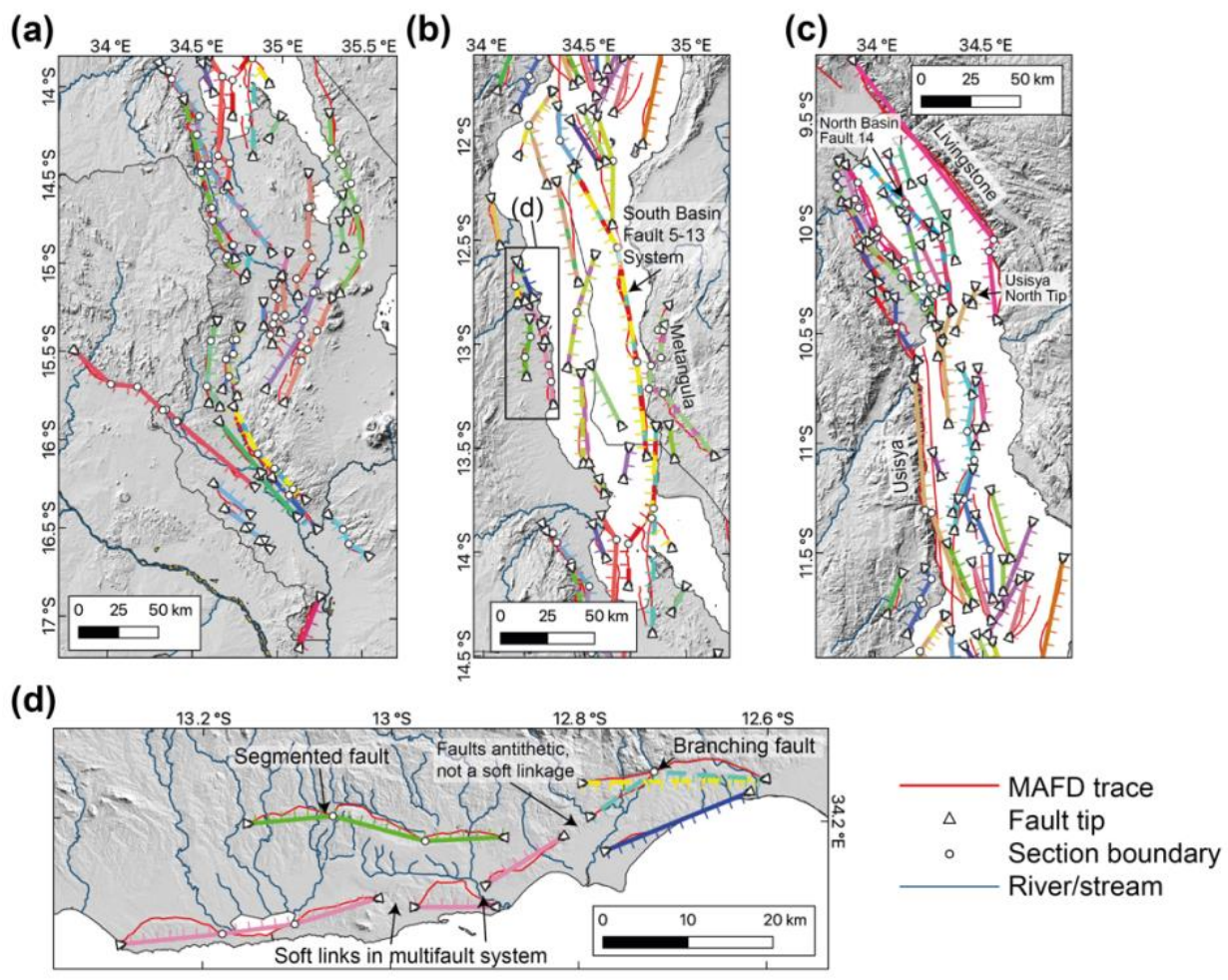

195 Figure 2: Maps for (a) southern Malawi, (b) South Basin, and (c) Central and North Basins of Lake Malawi showing the simplified geometry of faults in the Malawi Seismogenic Source Database (MSSD). (d) Criteria used to define MSSD sources in central Malawi. The MSSD sources are connected by straight lines between fault tips (triangles) or section boundaries (circles), and colored by each multi-fault or fault system. Ticks indicate dip direction. Dashed or multi-colored sources indicate branching geometries. Thin red lines are the MAFD fault traces (Williams et al., 2021c), and they highlight instances where a MAFD fault is not included in the MSSD, or there is a discrepancy between the MAFD and simplified fault geometry in the MSSD. 
'Multi-fault' seismogenic sources are identified in the MSSD where the tips of synthetic faults are closely spaced acrossstrike, as this may indicate that these faults interact through soft linkages via Coulomb stress changes (Biasi and Wesnousky, 2016; Hodge et al., 2018b; Mildon et al., 2016). Evidence for this behaviour in Malawi is indicated by the segmented nature of the 2009 Karonga earthquake sequence (Biggs et al., 2010; Fagereng, 2013; Macheyeki et al., 2015) and the bell-shaped along-strike displacement profiles of en-echelon faults in Lake Malawi (Contreras et al., 2000; Mortimer et al., 2016; Shillington et al., 2016). Empirical observations and Coulomb stress modelling indicate that en-echelon synthetic normal faults interact when the across-strike distance between two faults is $<20 \%$ of the combined length of the faults, up to a maximum separation of $10 \mathrm{~km}$ (Biasi and Wesnousky, 2016; Hodge et al., 2018b) and we use this to determine whether two or more distinct faults in the MSSD could rupture together (Fig. 2). Slip on a fault that is close to an across-strike antithetic fault exerts a negative Coulomb stress change on the antithetic fault (Mildon et al., 2016), and so these cases are not considered as multi-fault sources in the MSSD (Fig. 2d).

215 For fault sources, source length $\left(L_{s}\right)$ is the straight-line distance between fault tips (for unsegmented faults), or the cumulative straight-line distance between the individual section boundaries for segmented faults (Table 1; Fig. 2). Multifault source length is the sum of the length of each participating fault (Table 1). These estimates imply shorter lengths than a fault's mapped trace in the MAFD. However, the simplified geometries in the MSSD is consistent with other fault-based seismic hazard assessments (Basili et al., 2008; Faure Walker et al., 2021; Stirling et al., 2012), and with the hypothesis that complex surface fault traces in Malawi root onto sub-planar deep-seated (depths $>5 \mathrm{~km}$ ) weaknesses (Hodge et al., 2018a; Wedmore et al., 2020b). Following Christophersen et al., (2015) the minimum length of a MSSD source is $5 \mathrm{~km}$.

\subsubsection{MSSD Source Width}

We define the MSSD source geometry as 2D planes in 3D space by projecting the fault sources down-dip, and, in the case of faults in Lake Malawi that were mapped from the offset of the synrift basement surface (Scholz et al 2020), up-dip to the top of the sedimentary package (Figs. 3 and A1). The dip angles of the Livingstone, Chingale Step, Bilila-Mtakataka, Karonga, Kaporo and St Mary faults have been measured directly through either field measurements, geophysical surveys, or microseismicity (Gaherty et al., 2019; Kolawole et al., 2018a; Stevens et al., 2021; Wedmore et al., 2020a; Wheeler and Rosendahl, 1994) and these are applied when projecting faults down-dip. The moderately-steeply dipping $\left(40-65^{\circ}\right)$ planar faults indicated by these studies are also used to justify placing a $53^{\circ}$ dip estimate for sources in Malawi where no direct evidence for dip is currently available. The dips and kinematics of linking sections in Malawi have not been directly measured, however, they show distinct dip-slip scarps, and do not coincide with along-strike minima in scarp height or footwall relief (Wedmore et al., 2020b). These linking sections are therefore interpreted as dip-slip planes that dip at the same angle as the adjoining sections, rather than vertically dipping strike-slip sections (Acocella et al., 1999). 
Width $(W)$ in the MSSD represents the width of an earthquake a source may host. For relatively short section sources, $W$ will therefore be less than the width of the larger fault or multi-fault structure they are contained within in the MSSD geometrical model (Fig. 3). In practice, this implies that section ruptures can float at a range of depth intervals on a larger fault plane (Pagani et al., 2014), and so do not necessarily propagate to the surface; indeed, the possible blind rupture of a northern section of the Bilila-Mtakataka Fault during the $\mathrm{M}_{\mathrm{W}} 6.31989$ Salima Earthquake may be an example of such an event (Hodge et al., 2018a; Stevens et al., 2021).

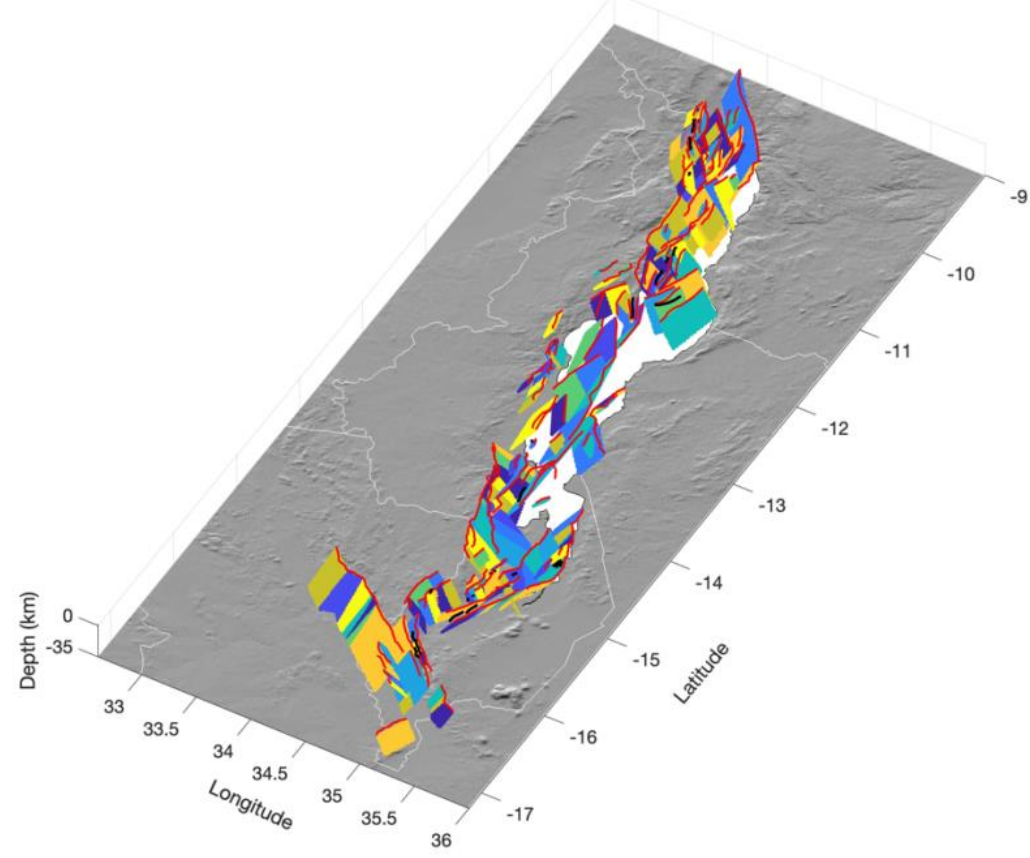

Figure 3: 3D geometrical model of all MSSD sources. Each 2D plane represents a distinct along-strike MSSD section or fault. Red and black lines are the fault traces from the Malawi Active Fault Database (MAFD) that are, and are not, included in the MSSD, respectively. Image underlain by SRTM DEM.

In the first instance, $W$ is assigned based on an empirically-derived scaling relation between $W$ and $L_{s}$ (Leonard, 2010), which are self-consistent with earthquake magnitude and average single event displacement estimates (Sect. 3.3). For dipslip faults, Leonard, (2010) relations assume that $W$ is unlimited by the thickness of the seismogenic layer. In central and northern Malawi however, faults and multi-fault systems may reach lengths $>140 \mathrm{~km}$, which assuming fault dips of $\sim 50-60^{\circ}$, would imply ruptures at depths $>40 \mathrm{~km}$. This would be deeper than the $30-40 \mathrm{~km}$ thick seismogenic layer in Malawi (Ebinger et al., 2019; Stevens et al., 2021) and would imply that ruptures propagate into the upper mantle. Although upper mantle earthquakes have been recorded in Malawi (Yang and Chen, 2010), our preferred interpretation is that ruptures along 
faults in the MSSD will not exceed depths of 30-40 km since: (1) mechanically, it is easier for dip-slip ruptures to propagate up-dip rather than down-dip (Das and Scholz, 1983) and (2) estimates of fault width in earthquake scaling relationships are derived from aftershock distributions, and for dip-slip faults, these events do not generally nucleate below the portion of the crust that is seismogenic (Henry and Das, 2001). In the MSSD, $W$ is therefore calculated as:

$W=\left\{\begin{array}{c}c_{1} L_{s}{ }^{2 / 3}, \text { if } c_{1} L_{s}{ }^{2 / 3}<\frac{z}{\sin \delta} \\ \frac{z}{\sin \delta}, \text { if } c_{1} L_{s}{ }^{2 / 3} \geq \frac{z}{\sin \delta}\end{array}\right.$

where $c_{1}$ is an empirically derived parameter (for interplate dip-slip faults $>5 \mathrm{~km}$ long; Leonard, 2010), $\delta$ is fault dip (assigned $53^{\circ}$, unless otherwise measured), and $z$ is the thickness of the seismogenic layer, for which we use an intermediate estimate of $35 \mathrm{~km}$.

Following these first estimates for $W$, we then test whether the down-dip extent of a MSSD source implies that it will intersect with another source at depth (Fig. A1). In this way, we accommodate observations from Malawi and elsewhere that such dip intersections can pose significant barriers to earthquake rupture and/or one of the intersecting faults is truncated by the intersection (Gaherty et al., 2019; King, 1986; Plesch et al., 2007; Walters et al., 2018). In the case where two 2D planes in the MSSD intersect at depth, we assume that the shorter -and presumably lower displacement- source has been truncated and locked by the longer source (Fig. A1; Scholz and Contreras, 1998). Furthermore, if the across-strike distance at the surface between two intersecting sources is $<6 \mathrm{~km}$, which is the maximum across-strike distance that two sources dipping at $53^{\circ}$ and with widths $<5 \mathrm{~km}$ will intersect, we omit the shorter of the two sources in the MSSD. Following these criteria, and the removal of other sources $<5 \mathrm{~km}$ long (Sect. 3.3.1), 22 faults in the MAFD are not included in the MSSD (Fig. 3, Table S1). This does not imply that these structures cannot host earthquakes but instead that: (1) there are few historical observations of surface ruptures $<5 \mathrm{~km}$ long (Baize et al., 2019), and this increases the uncertainty in applying earthquake scaling relationships to these faults (Christophersen et al., 2015; Stirling et al., 2013), and (2) there are many hitherto unmapped short $(<10 \mathrm{~km}$ ) faults in Malawi (Williams et al., 2021c), and so during PSHA, it may be more appropriate that moderate magnitude seismicity along them is incorporated using off-fault distributed sources (e.g., Hodge et al., 2015; Stirling et al., 2012).

\subsection{Slip Rates}

280 For the MSSD sources in the North Basin of Lake Malawi, slip rates are derived from estimates that were previously made using the vertical offset of a 75 ka megadrought horizon in seismic reflection data (Scholz et al., 2007; Shillington et al., 2020). The offset-reflector slip rate estimates are preferred in the MSSD instead of the geodetic-based estimates (described below), as: (1) they represent on-fault measurements and (2) they represent the slip accumulated over multiple earthquake 
cycles, and so are more representative of a source's long term behaviour (Cowie and Roberts, 2001; DuRoss et al., 2020).

The uncertainty in using the offset seismic reflector to derive slip rates is discussed in Sect. 3.4.

Slip rates are derived from geodesy using a 'systems-based' approach that partitions the regional geodetic extension rate onto rift faults in a manner consistent with observations and theory of regional strain distribution in narrow magma-poor continental rifts (Williams et al., 2021b). We first group the MSSD sources in central and northern Malawi into the North, South, and Central Basins (Scholz et al., 2020; Shillington et al., 2020), and in southern Malawi into the Makanjira, Zomba, Lengwe (previously referred to as the "Mwanza"), Lower Shire, and Nsanje basins (Fig. 1b; Williams et al., 2021b). We then divide the MSSD sources depending on whether they are part of an intra-rift or border fault system. Border faults are classified geometrically in the MSSD as the faults at the edge of the rift (Ebinger, 1989; Muirhead et al., 2019; Williams et al., 2021b). The slip rate for each MSSD source, $s$, is then estimated through:

slip rate $(s)=\left\{\begin{array}{l}\frac{v \alpha_{b f} \cos \left(\theta_{s}-\phi\right)}{n_{b f} \cos \delta}, \text { for border fault sources } \\ \frac{v \alpha_{i f} c_{h w f} \cos \left(\theta_{s}-\phi\right)}{n_{i f} \cos \delta}, \text { for intrarift sources }\end{array}\right.$

where $\theta_{s}$ is the source's slip azimuth, $v$ and $\varphi$ are the geodetically-derived horizontal rift extension rate and azimuth, $c_{h w f}$ is a correction factor for hanging-wall flexural extension, $\alpha$ is a weight that depends on whether the source is hosted on a border $\left(\alpha_{b f}\right)$ or intrarift $\left(\alpha_{i f}\right)$ fault system, and it is divided by the number of mapped border $\left(n_{b f}\right)$ or intrarift $\left(n_{i f}\right)$ fault or multi-fault systems in each basin. Uncertainty in these parameters is discussed in Sect. 3.4.

In the MSSD, the rift extension rate $(v)$ and azimuth $(\varphi)$ are derived from the geodetic model developed by Wedmore et al., (2021) in which southern Africa is divided into two microplates (San and Rovuma) that move independently of the Nubian Plate (Fig. 1). The Euler Pole for the relative motion between San and Rovuma (as defined by a location and rotation rate) and associated uncertainties are used to calculate the plate motion and its uncertainty at the centre of each basin following the methods of Robertson et al (2016) (Table 2, Fig. 1). The MSSD sources are assumed to exhibit pure normal dip-slip, which is consistent with fault slickensides and focal mechanisms (Delvaux and Barth, 2010; Hodge et al., 2015; Wedmore et al., 2020a; Williams et al., 2019), and so the slip azimuth $(\theta)$ is parallel to the source's dip direction.

310 Table 2: Plate motion vector for each basin in Malawi using the geodetic model by Wedmore et al., (2021) and the coordinates from which it was derived. The uncertainties associated with each vector are derived using the methods presented by Robertson et al., (2016). For basins in southern Malawi, the Nubia-Rovuma plate motion vectors obtained from the Saria et al., (2013) geodetic model (S13) and used in the South Malawi Seismogenic Source Database are also reported. 


\begin{tabular}{|c|c|c|c|c|c|}
\hline Basin & $\begin{array}{l}\text { Centre of basin } \\
\text { longitude (E) }\end{array}$ & $\begin{array}{l}\text { Centre of } \\
\text { basin latitude } \\
\text { (S) }\end{array}$ & $\begin{array}{l}\text { Geodetic } \\
\text { Model }\end{array}$ & $\begin{array}{l}\text { Velocity and uncertainty } \\
\text { of plate motion }(\mathrm{mm} / \mathrm{yr})\end{array}$ & $\begin{array}{l}\text { Azimuth, and azimuthal } \\
\text { uncertainty of plate } \\
\text { motion }\end{array}$ \\
\hline $\begin{array}{l}\text { North } \\
\text { Basin }\end{array}$ & 34.18 & 9.93 & W21 & $1.28 \pm 0.38$ & $076^{\circ} \pm 016^{\circ}$ \\
\hline $\begin{array}{l}\text { Central } \\
\text { Basin }\end{array}$ & 34.46 & 11.16 & W21 & $1.11 \pm 0.30$ & $076^{\circ} \pm 017^{\circ}$ \\
\hline $\begin{array}{l}\text { South } \\
\text { Basin }\end{array}$ & 34.57 & 13.09 & W21 & $0.91 \pm 0.22$ & $074^{\circ} \pm 022^{\circ}$ \\
\hline \multirow[t]{2}{*}{ Makanjira } & 34.88 & 14.52 & W21 & $0.75 \pm 0.18$ & $073^{\circ} \pm 027^{\circ}$ \\
\hline & & & S13 & $1.08 \pm 1.66$ & $075^{\circ} \pm 089^{\circ}$ \\
\hline \multirow[t]{2}{*}{ Zomba } & 34.93 & 15.43 & W21 & $0.66 \pm 0.17$ & $071^{\circ} \pm 032^{\circ}$ \\
\hline & & & S13 & $0.88 \pm 1.65$ & $072^{\circ} \pm 110^{\circ}$ \\
\hline \multirow{2}{*}{$\begin{array}{l}\text { Lower } \\
\text { Shire }\end{array}$} & 35.08 & 16.23 & W21 & $0.57 \pm 0.18$ & $070^{\circ} \pm 037^{\circ}$ \\
\hline & & & S13 & $0.69 \pm 1.65$ & $069^{\circ} \pm 141^{\circ}$ \\
\hline \multirow[t]{2}{*}{ Nsanje } & 35.23 & 17.28 & W21 & $0.57 \pm 0.21$ & $067^{\circ} \pm 048^{\circ}$ \\
\hline & & & S13 & $0.46 \pm 1.63$ & $063^{\circ} \pm 212^{\circ}$ \\
\hline Lengwe & 34.33 & -15.88 & W21 & $0.61 \pm 0.16$ & $065^{\circ} \pm 037^{\circ}$ \\
\hline
\end{tabular}

315

Lower, intermediate, and upper $\alpha_{b f}$ values of $0.5,0.7$, and 0.9 are applied in the MSSD. These values reflect observations of the relative contribution to rift opening between intrarift and border faults in Malawi (Shillington et al., 2020; Wedmore et al., 2020a), elsewhere along the EAR (Kolawole et al., 2021b; Muirhead et al., 2016, 2019; Wright et al., 2020), and in analogue and numerical models (Agostini et al., 2011; Gupta et al., 1998). The South Basin is bound onshore by the Metangula Fault (Laõ-Dávila et al., 2015). However, Flannery and Rosendahl, (1990) have previously interpreted that the South Basin 5-13 multi-fault system, which lies 5-20 km across strike under Lake Malawi (Fig. 2b), is also a border fault given its relatively large length-scale $(>200 \mathrm{~km})$ and high throw $(>\sim 2 \mathrm{~km}$, as derived from variations in the thickness of synrift sediments across it; Scholz et al., 2020). We acknowledge this in the MSSD by interpreting the South Basin 5-13 multi-fault system by distributing $\alpha_{b f}$ equally between it and the Metagula Fault.

The considerable throw (>5 km) along border fault systems in central and northern Malawi induces a significant amount of downward flexure within the rift floor, which is accommodated by intrarift faults (Muirhead et al., 2016; Olive et al., 2014; Petit and Ebinger, 2000). Thus, when considering the slip rate of intrarift sources, the contribution from both regional 
extensional strain and local flexural strain must be considered. The latter, however, is not sampled by far-field geodetic measurements (Muirhead et al., 2016; Shillington et al., 2020). In Eq. 2, we therefore apply a correction factor $\left(c_{h w f}\right)$ to account for the flexural strain that intrarift sources in Malawi are accommodating, and which is not directly incorporated into $v$. We define $c_{h w f}$ as:

$c_{h w f}=\frac{1}{\left(T_{i f-e x t}-h w f_{\text {ext }}\right) / T_{\text {if-ext }}}$

where $T_{i f-e x t}$ is the estimated total cumulative extension across a basin's intrarift sources (Appendix A), and $h w f f_{\text {ext }}$ is the flexural extension across the basin as modelled following a broken-plate model (Figs. 4 and A3; Tables A2 \& A3; Billings and Kattenhorn, 2005; Muirhead et al., 2016; Shillington et al., 2020; Turcotte and Schubert, 1982). The calculated profiles across these basins cannot determine which intrarift sources will accommodate disproportionately more or less flexural strain (Fig. 4), and so each intrarift source in a given basin is assigned the same range of $c_{h w f}$ values. Hanging-wall flexural modelling in the basins south of Lake Malawi indicates negligible flexural extension due to the much lower throws $(<1 \mathrm{~km})$ on the region's border faults (Fig. A3), and so $c_{h w f}$ is set to one for these basins.

(a)

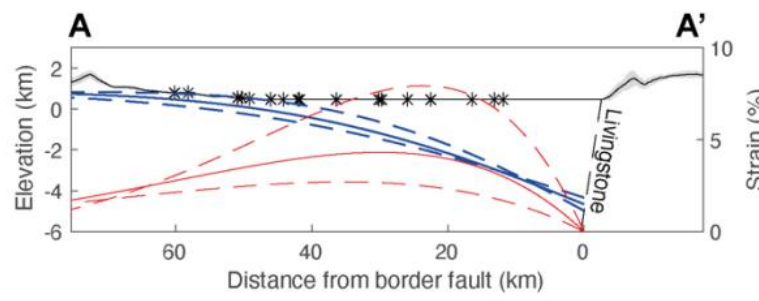

(b)

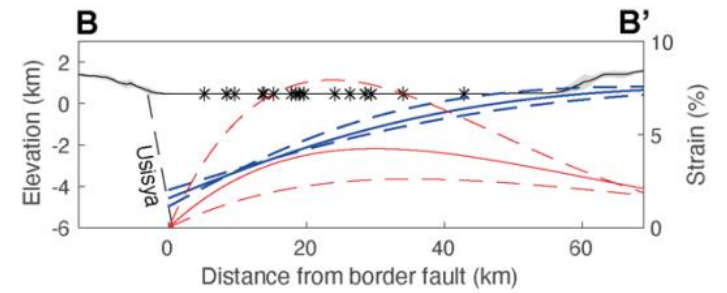

(c)

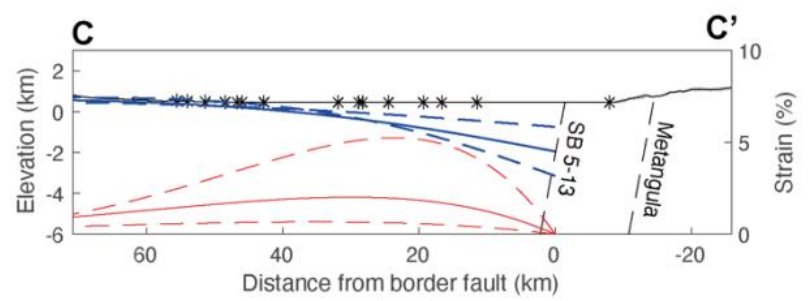

(d)
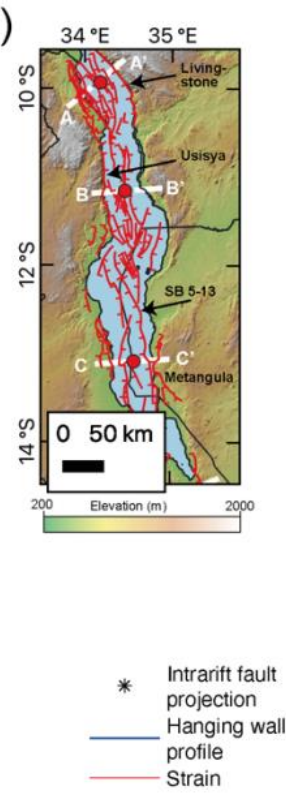

Figure 4: Representative hanging-wall flexural and flexural strain profiles through the (a) North, (b) Central and (c) the South Basins of Lake Malawi. For each profile, a solid line indicates the median value, and dashed lines indicate upper and lower estimates using previous estimates of fault throw (Accardo et al., 2018; Shillington et al., 2020) and the parameters listed in Table A2. Solid black line and gray shading represents mean and one standard deviation topography from (a) SRTM 
$30 \mathrm{~m}$ DEM, and (b\&c) TanDEM-X $12 \mathrm{~m}$ DEM in $10 \mathrm{~km}$ swath (Schwanghart and Scherler, 2014) on profile locations shown in (d). Profiles have 3x vertical exaggeration. Note, in (c) there is uncertainty about whether flexural strain should be projected from the South Basin 5-13 or Metangula faults, but this does not affect our estimates of the magnitude of flexural strain, or how it may be distributed across different intrarift faults.

\subsection{Earthquake magnitudes and recurrence intervals}

We apply empirically derived earthquake scaling relationships to estimate the magnitude and average single event displacement of an earthquake along a MSSD source. For consistency with estimates of a source's area, we use the Leonard, (2010) relations to calculate these parameters. Inherent in the Leonard, (2010) magnitude scaling relationships for dip-slip faults are that $L_{s}$ scales with $W$ following Eq. 1, however, this scaling breaks down for MSSD sources whose down-dip extent is limited by an intersecting source or the thickness of the seismogenic layer (Sect. 3.1.2). We therefore adapt the model that Leonard (2010) applied for width-limited strike-slip ruptures, which indicates that seismic moment $\left(M_{0}\right) \propto L_{s}{ }^{1.5}$ and $\bar{D}=c_{2} \sqrt{A_{s}}$, where $A_{s}$ is source area and equals $L_{s} z / \sin \delta, c_{2}$ is an empirically derived constant, and $\bar{D}$ is average single event displacement. The earthquake magnitude of source $s$ in the MSSD therefore equals:

$M_{W}(s)=\left\{\begin{array}{c}\frac{\frac{5}{2} \log L_{S}+\frac{3}{2} \log c_{1}+\log c_{2} \mu-9.05}{1.5}, \text { if } c_{1} L_{S}{ }^{2 / 3}<\frac{z}{\sin \delta} \\ \frac{\frac{3}{2} \log A_{S}+\log c_{2} \mu-9.05}{1.5}, \text { for truncated sources or if } c_{1} L_{S}{ }^{2 / 3}>\frac{z}{\sin \delta}\end{array}\right.$

and $\bar{D}$ is:

$\bar{D}(s)=\left\{\begin{array}{c}10^{\frac{5}{6} \log L_{s}+\frac{1}{2} \log c_{1}+\log c_{2} \mu}, \text { if } c_{1} L_{s}{ }^{2 / 3}<\frac{z}{\sin \delta} \\ c_{2} \sqrt{A_{s}} \text { for truncated sources or if } c_{1} L_{s}{ }^{2 / 3}>\frac{z}{\sin \delta}\end{array}\right.$

where $\mu$ is the shear modulus ( $33 \mathrm{GPa}$; Leonard, 2010), and $z$ is $35 \mathrm{~km}$, as used in Eq. 1. Estimates of $\mathrm{M}_{\mathrm{W}}$ and slip rates are then combined to calculate recurrence intervals $(R)$ through the relationship $R=\bar{D} /$ slip rate (Wallace, 1970).

\subsection{Uncertainty in the MSSD}

There is considerable uncertainty in the variables used to calculate the slip rate and recurrence interval estimates in the MSSD, which is captured as described below. For the slip rates derived by Shillington et al., (2020) in the North Basin of Lake Malawi from the offsets on the $75 \mathrm{Ka}$. megadrought horizon in seismic reflection data, the primary source of uncertainty is, at these shallow depths, associated with the vertical resolution of the seismic reflection data, which is controlled by the frequency content of the data and the signal -to -noise ratio. The vertical resolution of seismic reflection data is typically estimated to be a quarter of the wavelength $(\lambda / 4)$ of the seismic data (Widess, 1973), though some authors report detecting faults with much smaller offsets in data with low noise (e.g., $\lambda / 30$; Brown, 2011; Faleide et al., 2021). The 
dominant frequency of the relevant depth range of the seismic reflection data assessed by Shillington et al., (2020) is 40-60 $\mathrm{Hz}$, and so $\lambda \sim 25-37.5 \mathrm{~m}$. For the purposes of this study, we apply the $\lambda / 4$ rule, a velocity of $1500 \mathrm{~m} / \mathrm{s}$ and $50 \mathrm{~Hz}$, which gives an uncertainty of $7.5 \mathrm{~m}$; however, we consider this a very conservative estimate since we can identify much smaller fault offsets in some places. In addition, the reflector's age, which was obtained from Optically Stimulated Luminescence (OSL) dating of a drill-core interval that was tied to the reflector (Scholz et al., 2007), has a \pm 5,290 year uncertainty associated with it, and there a range of plausible fault dips the vertical offset measurement could be projected into $\left(40-65^{\circ}\right)$.

To quantify the uncertainties of these slip rate estimates, we follow the probabilistic framework of Zechar and Frankel, (2009). Specifically, we treat the OSL drill-core date as a normal distribution, and the slip measurement uncertainty (i.e., the combination of the vertical offset and fault dip uncertainties) as a boxcar function. Where multiple offset measurements of the reflector have been made for the same fault, a single offset probability distribution function ( $p d f$ ) is derived from normalizing the sum of the individual offset $p d f s$ (Zechar and Frankel, 2009). The resulting slip rate of each fault is then also treated as a normal $p d f$, albeit with a truncation for slip rates $<0$ (Zechar and Frankel, 2009). For multi-fault sources whose slip rate is measured from the offset reflector, the slip rate and slip rate uncertainty is derived from the area-weighted average slip rate of the participating fault sources.

390 Uncertainty in the parameters used to estimate slip rates and earthquake recurrence intervals from the systems-based approach is addressed through a logic tree (Fig. 5). A common interpretation of a logic tree is that all possible branch combinations represent a mutually exclusive and collectively exhaustive (MECE) set of events (Bommer and Scherbaum, 2008). However, it is difficult to interpret the results of logic trees using an MECE approach, as strictly speaking it implies that only one (unknown) outcome is correct, and all other branches provide no other information (Bommer and Scherbaum,

395 2008; Marzocchi et al., 2015). In the MSSD, we therefore sample epistemic uncertainty by incorporating the "relaxed view" of logic trees (Cramer et al., 1996; Gerstenberger et al., 2020; Marzocchi et al., 2015). In this context, uncertainty is defined nonparametrically by the variability of outcomes from the logic tree itself. Specifically, we calculate a slip rate and recurrence interval for each MSSD source in 10,000 Monte Carlo simulations of the logic tree in Fig. 5. We then fit a normal distribution, truncated at values $<0$, to the slip rate simulation results (Fig. 6a), and since it is calculated through a log function in Eq. 4, a log normal distribution to the recurrence intervals $R$ (Fig. 6b).

When sampling the MSSD logic tree, we treat parameters that have been described by standard deviations $(\sigma)$ about a mean value as a continuous normal distribution in the simulations (Fig. 5). Parameters assigned based on a range of observed values in Malawi (e.g., fault dip) are discretized into three equally weighted values based on an expert judgement (Fig. 5).

405 We note that there are pitfalls with using expert judgements in logic trees, however, for a tree with many branches, the outcomes are generally insensitive to the weightings, and it is the values at each logic tree step that are of importance (Bommer and Scherbaum, 2008). 
For simplicity, the slip rate and $R$ reported for each source are the mean values from the distributions fitted to the simulation results, and the upper and lower reported values represent $1 \sigma$ uncertainty (Fig. 5, Table 1). In this context, the upper and lower values of slip rate and $R$ represent our certainty in these parameters at a $68 \%$ confidence level. However, should a user of the MSSD wish to derive the uncertainty in slip rate and $R$ at different confidence levels, they will be able to do so through the reported values.

\subsection{Slip rate comparison}

415 There are 11 MSSD fault sources in the north basin of Lake Malawi in which slip rates can be derived from the offset of a 75 Ka seismic reflector (Shillington et al., 2020) and from the systems-based approach. Since in both cases, the slip rates are expressed as normal distributions that are truncated for values $<0$ (Sect. 3.4), we performed the following statistical tests to test how well these independent estimates of fault slip rates compare: (1) a two sample t-test for the null hypothesis that 10,000 values randomly drawn from the two slip rate distributions come from a distribution with the same mean, but since calculation of the overlapping coefficient (OVL; Clemons and Bradley, 2000; Inman and Bradley Jr, 1989)) between probability distributions $f_{1}(x)$ and $f_{2}(x)$ :

$O V L=\int \min \left[f_{1}(x), f_{2}(x)\right] \cdot d x$

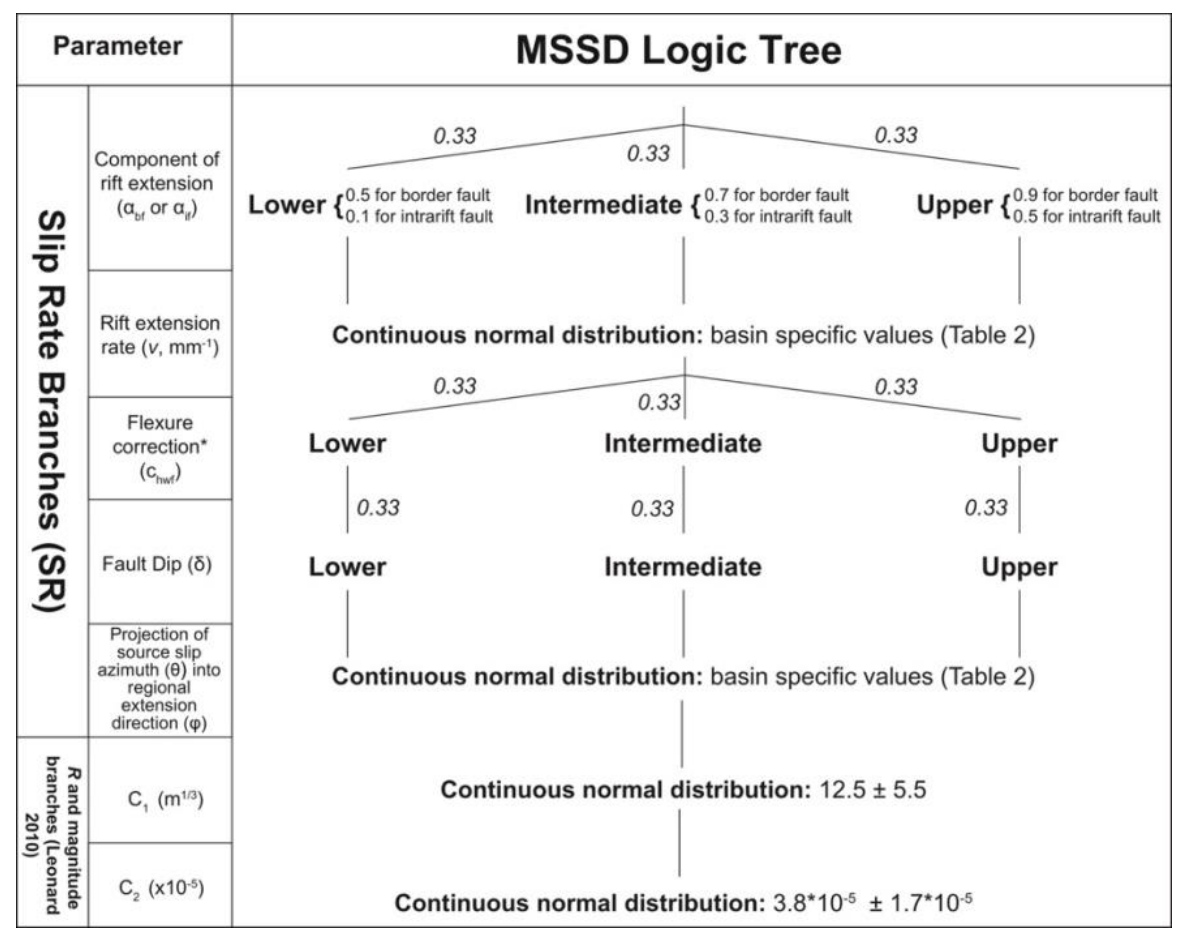


Figure 5: Logic tree branches through which Monte Carlo simulations are performed to describe uncertainty in the MSSD. Continuous parameters are sampled from a normal distribution. If this results in a slip rate $<0$, the slip rate is truncated accordingly. Not all possible logic tree branches are represented above. Instead, those from which we can obtain extreme lower, intermediate, and upper slip rate and recurrence interval estimates are shown. *Flexure correction step only performed for intrarift sources in Lake Malawi (Sect. 3.2).

\section{Results}

\subsection{MSSD overview}

The Malawi Seismogenic Source Database (MSSD) provides geometric, kinematic, and seismogenic information about 248 possible earthquake sources in Malawi and its surrounding region. These are divided into 104 'fault' sources, 117 'section' sources, and 27 'multi-fault' sources. Mean slip rate estimates are 0.05-0.3 $\pm 0.05 \mathrm{~mm} / \mathrm{yr}$ for intrarift sources and 0.5-1.5 $\pm 0.3 \mathrm{~mm} / \mathrm{yr}$ for sources hosted on border fault systems (Fig. 7, Table 3). There is an overall increase in slip rates from south to north across Malawi (Fig. 7d-f) due to higher EAR extension rates as distance from the San-Rovuma Euler Pole increases (Fig. 1; Wedmore et al., 2021) and, for intrarift sources, the contribution of hanging-wall flexure to slip (Shillington et al., 2020). There are more multi-fault sources in central and northern Malawi (Fig. 7d-f), although we cannot distinguish 440 whether this reflects how fault tips are mapped in the DEMs and seismic reflection data, or if this reflects that previously distinct faults are beginning to interact and coalesce in this more evolved part of the EAR
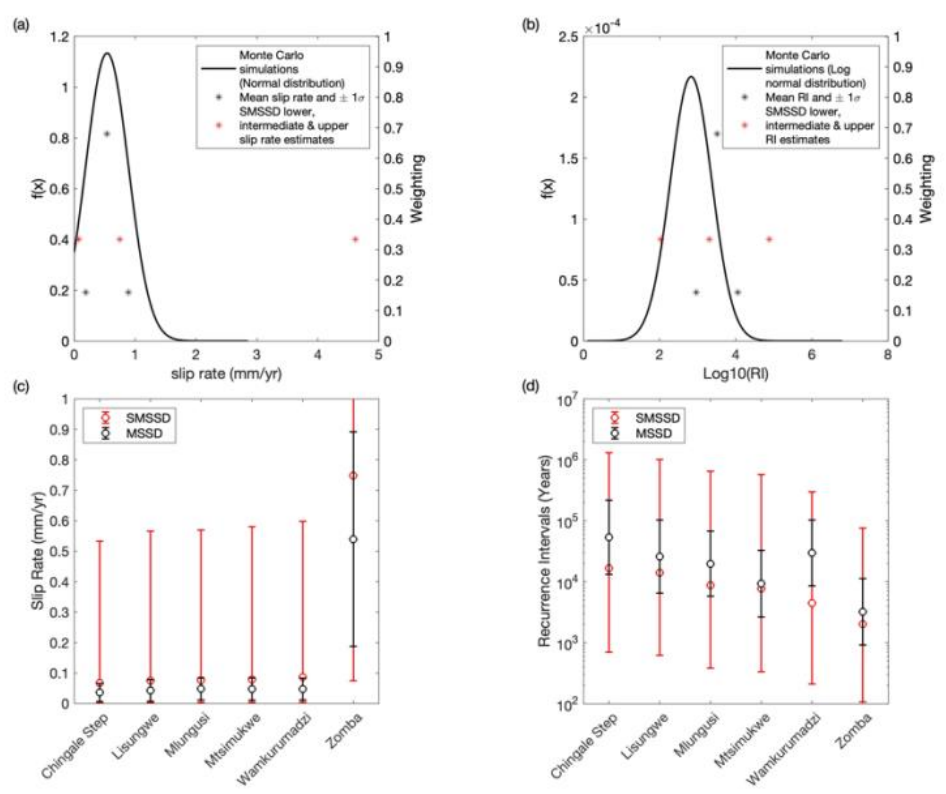

Figure 6: Comparison of uncertainty between the Malawi Seismogenic Source Database (MSSD) and the South Malawi Seismogenic Source Database (SMSSD; Williams et al., 2021b). (a) Slip rate for the Zomba fault modelled from the extreme 
445 cases of the logic tree (SMSSD) and from 10,000 Monte Carlo simulations through the logic tree (Fig. 5) and then fit to a normal distribution truncated at zero (MSSD). For the MSSD, results can also be discretized by the mean value \pm 1 standard deviation $(\sigma)$. For the SMSSD, no weighting was formally assigned to either estimate and so is depicted here as three equal weightings. (b) Equivalent to (a) but for the Zomba Fault recurrence interval $(R)$, which follows a log normal distribution. Comparison of (c) mean slip rate and (d) mean recurrence interval estimates for all faults in the Zomba Graben between the SMSSD and MSSD. Error bars represent extreme values (SMSSD) and $1 \sigma$ (MSSD).

The mean and range of intermediate earthquake magnitude estimates for section sources in the MSSD is $\mathrm{M}_{\mathrm{W}} 6.3$ and $\mathrm{M}_{\mathrm{W}}$ 5.4-7.6, $\mathrm{M}_{\mathrm{W}} 6.8$ and $\mathrm{M}_{\mathrm{W}}$ 5.4-7.6 for fault sources, and $\mathrm{M}_{\mathrm{W}} 7.3$ and $\mathrm{M}_{\mathrm{W}}$ 6.7-8.1 for multi-fault sources (Fig. 7, Table 3). Twenty-eight sources are identified that are capable of hosting $\mathrm{M}_{\mathrm{W}}>7.5$ earthquakes with the largest magnitude source $\left(\mathrm{M}_{\mathrm{W}}\right.$ 455 8.1) being the $268 \mathrm{~km}$ long South Basin Fault 5-13 multi-fault system (Fig. 2b). Smaller source lengths imply shorter intermediate recurrence intervals for section sources ( 500-30,000 years) than on fault and multi-fault systems $(1,000-40,000$ years). The standard deviation $(1 \sigma)$ uncertainties for slip rates are $0.05-0.3 \mathrm{~mm} / \mathrm{yr}$ and for recurrence intervals, $1 \sigma$ uncertainty is approximately one order of magnitude (Fig. 6).

460 Table 3: Range of selected attributes in the MSSD. Analysis is for mean value of each attribute

\begin{tabular}{lccc}
\hline MSSD Parameter & Min & Mean & Max \\
\hline Border fault slip rate (mm/yr) & 0.18 & 0.74 & 2.0 \\
Intrarift fault slip rate (mm/yr) & 0.03 & 0.13 & 0.6 \\
Section magnitude & 4.8 & 6.3 & 7.7 \\
Fault magnitude & 5.6 & 6.8 & 7.9 \\
Multi-fault magnitude & 6.6 & 7.4 & 8.1 \\
Section recurrence interval (years) & 390 & 5700 & 31460 \\
Fault recurrence interval (years) & 370 & 10900 & 85700 \\
Multi-fault recurrence interval (years) & 2720 & 12400 & 41700 \\
\hline
\end{tabular}




\subsection{Slip rate estimate comparisons in Lake Malawi}

Of the 11 intrarift fault sources in the North Basin of Lake Malawi whose slip rate estimate could be compared, the mean slip rate from the $75 \mathrm{Ka}$ offset reflector is within $2 \sigma$ of the mean slip rate derived from the systems-based approach for 9 faults (Fig. 8). However, in the case of the t-test, we reject the null hypothesis that the two slip rate estimates are from probability distribution functions with the same mean value at a 5\% significance level for all faults (Fig. 8). This reflects that slip rate estimates are higher for 9 out of 11 cases when they are derived from the offset reflector (Fig. 8).

We find that the overlapping coefficient (OVL) between the two slip rate probability distributions is $>0.5$ for 9 out of 11 faults. For the cases where OVL $<0.5$, one is for a fault interpreted as the northern tip of the Usisya border fault system, and so this result may reflect along-strike reductions in the slip rate of this multi fault system (Accardo et al., 2018; Contreras et al., 2000). The other case is for Fault 1 of Shillington et al., (2020) (North Basin Fault 14 in the MSSD, Fig. 2c), which considering its $2.5 \mathrm{~km}$ total throw, is a particularly high slip-rate intrarift fault. In both instances, these comparisons indicated that there is more along- and across-strike variation in the slip rate of intrarift faults in Malawi than suggested by the systems-based approach, where the only parameter that results in slip rate variations is the fault slip azimuth with respect to the regional extension direction (Eq. 2).
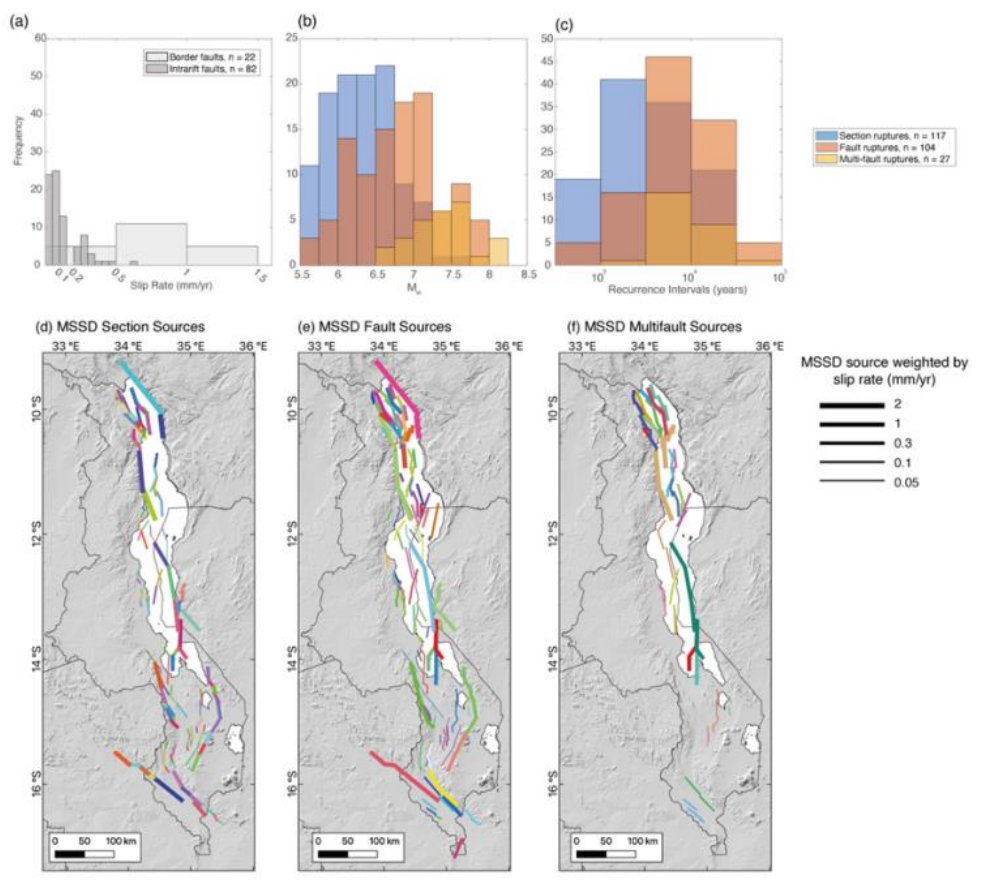

Figure 7: (a-c) Histograms for intermediate estimates of (a) fault slip rates, (b) magnitude estimates, and (c) recurrence intervals in the Malawi Seismogenic Source Database (MSSD). (d-f) Maps of (d) section, (e) fault, and (f) multifault sources in the MSSD, with lines weighted by the source's intermediate slip rate estimate. Each color represents a different source. 


\section{Discussion}

\subsection{Assessment of fault slip rate estimates in the MSSD}

The MSSD uses a new geodetic model for East Africa (Wedmore et al., 2021) compared to that used in the South Malawi Seismogenic Source Database (SMSSD; Saria et al., 2013; Williams et al., 2021b). Overall, the rift extension rates inferred from these models are broadly similar, so using the Wedmore et al., (2021) model does not significantly change the mean

485 slip rate estimate (Fig. 6). However, there is a significant reduction in the regional extension rate uncertainties (from \pm 1.5 $\mathrm{mm} / \mathrm{yr}$ to $\pm 0.3 \mathrm{~mm} / \mathrm{yr}$, Table 2). This demonstrates the importance of collecting new geodetic data in East Africa to reduce epistemic uncertainty in seismic hazard assessment.
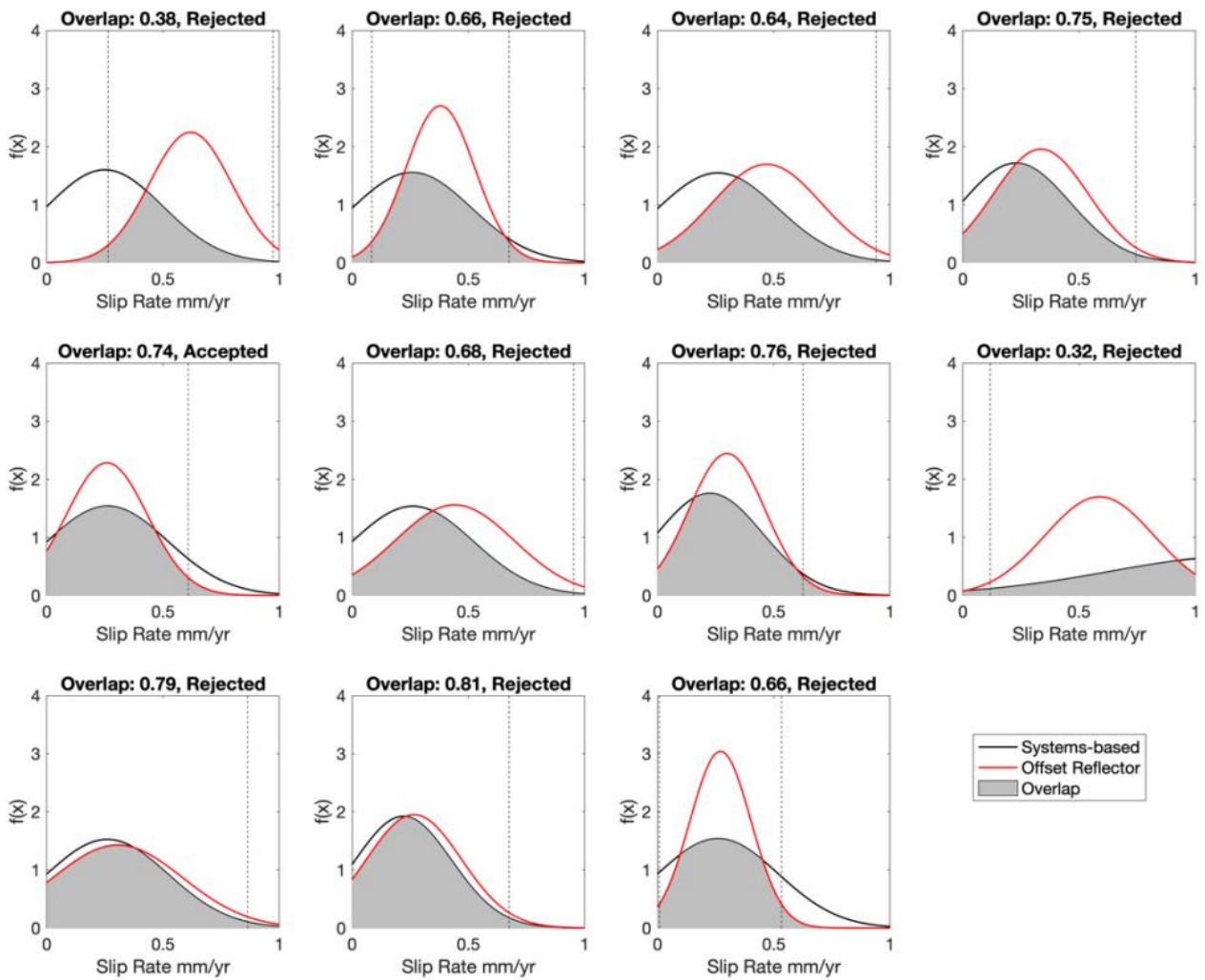

Figure 8: Comparison of the slip rate probability distribution for 11 intrarift faults in the North Basin of Lake Malawi when derived from the 'systems-based' approach and offset seismic reflector (Shillington et al., 2020). Dashed vertical lines indicate two standard deviations about the mean value of the offset-reflector slip rate distributions. For each plot the overlap 
coefficient between the two probability distributions (Eq. 6) and the result of the t-test to determine if the rates are from a probability distribution with the same mean value are also indicated. The t-test is rejected when $\mathrm{p}<0.05$.

By using the variability of logic tree outcomes to describe slip rates and recurrence intervals in the MSSD, we also provide a more thorough description of the epistemic uncertainty in these parameters than the SMSSD, which considered the extreme and intermediate logic tree branches only (Fig. 6c\&d). This approach could be used to model uncertainty in other regions where alternative hypotheses for slip rates and recurrence intervals have been explored using logic trees (Beauval et al., 2018; Vallage and Bollinger, 2020). Nevertheless, no MSSD slip rate estimates are 'well-constrained' under the test that a well-constrained slip rate is one where the median estimate is greater than the width of its $95 \%$ confidence interval (Bird and Liu, 2007; Zechar and Frankel, 2009).

For 9 out of 11 intrarift fault sources in Lake Malawi's North Basin, the mean slip rate estimate is higher when obtained from the measured offset of a $75 \mathrm{ka}$ seismic reflector (Shillington et al., 2020) than from a systems-based approach, which are contingent on geodetically derived regional extension rates (Fig. 8). The relatively low systems-based slip rate estimates may reflect the inadvertent inclusion of inactive faults when defining $n_{i f}$ in Eq. 2 for the North Basin. All offshore faults in this basin have been active within the past $75 \mathrm{Ka}$ (Shillington et al., 2020), however, we cannot exclude the possibility that some onshore faults are now inactive, even though they show evidence for EAR activity and/or are well oriented for reactivation in the regional stress state (Dawson et al., 2018; Kolawole et al., 2018a; Williams et al., 2021c). Alternatively, the proportion of regional extensional strain that is partitioned on to intrarift sources ( $\alpha_{i f}$ in Eq. 2 ) may be too low. The values we applied (0.5-0.9, Fig. 5) are consistent with observed cumulative intrarift and border fault extension in northern Malawi (Accardo et al., 2018; Shillington et al., 2020), however, it is possible, that over the lifetime of the EAR, disproportionately more strain is migrating onto intrarift faults (Biggs et al., 2010; Kolawole et al., 2018a; Wedmore et al., 2020a). The discrepancy between geologic and systems-based slip rates does not reflect temporal slip rate variations across an individual fault (Beanland and Berryman, 1989; Hetland and Hager, 2006), as we are considering the slip rate across the entire fault network in northern Malawi, and at this spatial scale, the cumulative slip rates of faults in continental rifts are generally stable over millennial timescales (Nicol et al., 2006). Nevertheless, although there is a discrepancy between the mean slip rate estimates from the offset reflector and systems-based approach, the high overlapping coefficient $(O V L>0.5$ for 9 out of 11 faults) between the two slip rate probability distribution, suggests that the latter approach is an appropriate method to estimate faults slip rates elsewhere in Malawi where no other constraints are currently available. With the collection of more geologic and geodetic data in Malawi, these slip rate estimates can be refined, and the existence, or not, of temporal slip rate variations clarified. 


\subsection{Earthquake magnitude estimates in the MSSD}

There are 28 sources in the MSSD that, given their geometry and the Leonard, (2010) scaling relationships (Eq. 4), can host $\mathrm{M}_{\mathrm{W}}>7.5$ earthquakes. If such an event was to occur, it would be amongst the largest recorded continental normal fault earthquakes (Middleton et al., 2016; Valentini et al., 2020; Xu et al., 2018). Indeed, it has been questioned whether $\mathrm{M}_{\mathrm{W}}>7.5$ continental normal fault earthquakes are physically possible due to the constraints imposed by smaller differential stresses and rupture widths in continental crust where the seismogenic layer is typically 10-20 km thick (Neely and Stein, 2021; Xu et al., 2018). However, we suggest that these factors do not limit earthquake magnitudes in Malawi given its cold, anhydrous, frictionally strong, and thick seismogenic layer (35 km; Ebinger et al., 2019; Fagereng, 2013; Hellebrekers et al., 2019; Jackson and Blenkinsop, 1993, 1997; Stevens et al., 2021). Furthermore, geomorphic analysis of the Billila-Mtakataka Fault scarp indicates high single event displacements ( 5-10 m), which is consistent with it hosting $\mathrm{M}_{\mathrm{W}}$ 7.4-8.0 earthquakes (Hodge et al., 2020). We also note our magnitude estimates are contingent on the hypothesis that source width will saturate at $L_{s}>140 \mathrm{~km}$ so that $M_{0} \propto L_{s}{ }^{1.5}$ (Leonard, 2010; Sect. 3.1.2). However, we cannot exclude the possibility that very long ruptures propagate below $35 \mathrm{~km}$. If true, then the MSSD underestimates magnitudes for sources with lengths $>140 \mathrm{~km}$

\subsection{Future directions for the MSSD}

Although the basic feature of the MSSD is an earthquake 'source,' it is not an exhaustive list of potential earthquake ruptures in Malawi as: 1) the MAFD is not a complete database of active faults in Malawi; particularly faults $<10 \mathrm{~km}$ long, or faults that do not show evidence for EAR displacement but that are still active (Williams et al., 2021c), 2) uncertainty in how faults intersect at depth in Malawi is not explored in the MSSD, and 3) the MSSD does not contain information about potential earthquakes that rupture multiple sections but not the whole length of a segmented fault. Indeed, earthquakes are not necessarily predisposed to conform to fault segment boundaries identified from empirically derived geometrical criteria (Kagan et al., 2012). This could be explored in future in the MSSD by distributing various event magnitudes across a wider fault system for a given moment rate and magnitude-frequency distribution (Visini et al., 2020; Youngs and Coppersmith, 1985).

It is implicit in the MSSD approach that the slip rate assigned to each source is released seismically. This is consistent with observed patterns of seismicity (Ebinger et al., 2019; Stevens et al., 2021) and the velocity weakening behaviour of representative basement samples from Malawi in deformation experiments at lower crustal pressures and temperatures (Hellebrekers et al., 2019). However, some shallow (depths $<6 \mathrm{~km}$ ) aseismic deformation was observed in northern Malawi following the $2015 \mathrm{M}_{\mathrm{w}} 5.2$ earthquake (Zheng et al., 2020). This could be addressed by dividing the MSSD recurrence intervals by a representative estimate of Malawi's crust's coupling coefficient (Bird and Liu, 2007). 


\section{Conclusions}

The Malawi Seismogenic Source Database (MSSD) is a freely available database that documents the geometry, slip rate, and earthquake magnitude and recurrence intervals of 248 possible earthquake sources in Malawi and neighboring Tanzania and Mozambique. It is distinct, but complementary to the Malawi Active Fault Database (Williams et al., 2021c). The MSSD also represents an update of the South Malawi Seismogenic Source Database (Williams et al., 2021b) due to the application of a new geodetic model (Wedmore et al., 2021), new active fault mapping (Kolawole et al., 2021a), and a more robust description of uncertainty.

The $>100 \mathrm{~km}$ length-scale of faults and multi-fault sources in the MSSD imply that Malawi may experience earthquakes $\mathrm{M}_{\mathrm{W}}$ >7.5. Such magnitudes, although rare for continental normal faults, are consistent with the crust's rheology in Malawi. Regional extensional rates of $0.5-1.5 \mathrm{~mm} / \mathrm{yr}$ imply the occurrence of such large magnitude events will be low $\left(10^{3}-10^{4}\right.$ years); however, the MSSD also documents the possibility of $\mathrm{M}_{\mathrm{W}}$ 5.5-6.5 earthquakes with recurrence intervals of $\sim 10^{3}$ years, and such events can also cause significant loss in Malawi (Goda et al., 2016; Gupta and Malomo, 1995). The data contained within the MSSD would allow the hazard of such events be formally assessed through probabilistic seismic hazard analysis.

Slip rates in the MSSD are estimated from either a systems-based approach that derives these rates from partitioning regional geodetic extension rates across faults, or, in Lake Malawi, direct measurements from the offset of a $75 \mathrm{Ka}$ seismic reflector (Shillington et al., 2020). Where it is possible to compare these estimates, we find that although those inferred from the offset reflector are higher, the two estimates are within error of each other. This suggests that the slip rates ( 0.05-3 mm/yr) estimated elsewhere in Malawi are meaningful. Hence, combining geodetic data with geological theory on regional strain distribution, active fault maps, and earthquake scaling relationships can provide important insights into the seismic hazard of other regions lacking historical or paleoseismic records.

\section{Appendix}

Below we provide an additional table and figure that provide extra detail to this study. Then in Appendix A, the hangingwall flexural analysis in Malawi is summarized.

580 Table A1: List of faults that are included in the Malawi Active Fault Database (MAFD; Williams et al., 2021b), but not the Malawi Seismogenic Source Database (MSSD). The reason for their removal from the MSSD is also listed.

\section{Fault Reason for not including in the MSSD}




\begin{tabular}{|c|c|}
\hline Nchalo & NW dip implies intersection with the Thyolo Fault with $<6 \mathrm{~km}$ across strike distance \\
\hline Mudi & Closely spaced $(2 \mathrm{~km})$ across strike from the Thyolo Fault, possible splay \\
\hline Jimbe & Closely spaced $(2 \mathrm{~km})$ across strike from the Lisungwe Fault, possible splay \\
\hline Chileka & Closely spaced $(5 \mathrm{~km})$ across strike from the Zomba Fault, possible splay \\
\hline Nguluwe & Closely spaced $(5 \mathrm{~km})$ across strike from the Zomba Fault, possible splay \\
\hline Lirangwe River & $<5 \mathrm{~km}$ long \\
\hline Linjidzi & $<5 \mathrm{~km}$ long \\
\hline Ngondo-1 & $<5 \mathrm{~km}$ long \\
\hline Ngondo-2 & $<5 \mathrm{~km}$ long \\
\hline Namiyala-1 & $\begin{array}{l}\text { Part of closely }(<2 \mathrm{~km}) \text { fault system at a bend in the Makanjira Fault. Likely a splay of this } \\
\text { larger fault system }\end{array}$ \\
\hline Namiyala-2 & $\begin{array}{l}\text { Part of closely }(<2 \mathrm{~km}) \text { fault system at a bend in the Makanjira Fault. Likely a splay of this } \\
\text { larger fault system }\end{array}$ \\
\hline Namiyala-3 & $\begin{array}{l}\text { Part of closely }(<2 \mathrm{~km}) \text { fault system at a bend in the Makanjira Fault. Likely a splay of this } \\
\text { larger fault system }\end{array}$ \\
\hline Chilongwelo & $\begin{array}{l}\text { E dip implies intersection with the South Basin 5-13 Fault system with }<6 \mathrm{~km} \text { across strike } \\
\text { distance }\end{array}$ \\
\hline Leopard Bay-2 & $<5 \mathrm{~km}$ long \\
\hline South Basin Fault 4 & E dip implies intersection with the South Basin 3 Fault with $<6 \mathrm{~km}$ across strike distance \\
\hline $\begin{array}{l}\text { Central Basin Fault } \\
4\end{array}$ & W dip implies intersection with Central Basin 6 Fault with $<6 \mathrm{~km}$ across strike distance \\
\hline $\begin{array}{l}\text { Central Basin Fault } \\
9\end{array}$ & Interpreted as linking structure between Central Basin Faults 9 and 22 \\
\hline
\end{tabular}


Central Basin Fault W dip implies intersection with Central Basin 11 Fault with $<6 \mathrm{~km}$ across strike distance 10

Central Basin Fault W dip implies intersection with Central Basin 20 Fault with $<6 \mathrm{~km}$ across strike distance 22

Hara Plain $\quad<5 \mathrm{~km}$ long

South Karonga East W dip implies intersection with South Karonga West Fault with $<6$ km across strike distance

Lupaso $\quad$ E dip implies intersection with Katesula Fault with $<6 \mathrm{~km}$ across strike distance

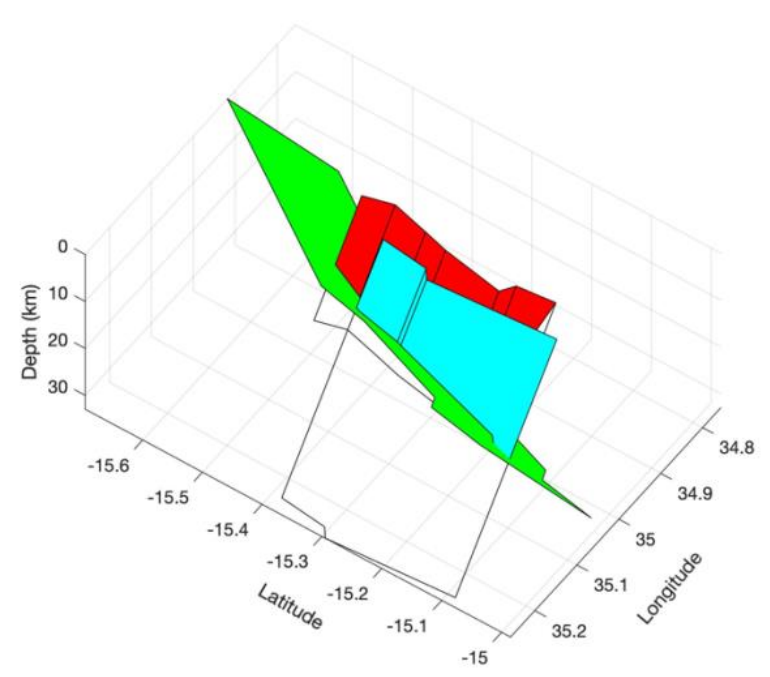

Figure A1: Examples of faults in the MSSD that are projected to intersect and where the across strike distance at the surface 585 is sufficient $(>6 \mathrm{~km})$ that they are interpreted to represent distinct sources. In this case the longer Chingale Step fault (green) is interpreted to have cut off the shorter Mlungusi (red) and Liwawadzi (cyan) faults, so that their geometry does not extend below the intersection, as indicated by transparent polygons. The revised cut off area of these faults is then used in the earthquake magnitude and single event displacement scaling relationships (Eqs. 4 and 5 in the main text).

\section{Appendix A: Hanging-wall flexure in Malawi}

590 The considerable amounts of throw (>1000 m) along a rift bounding fault can induce a significant amount of flexure within the lithosphere either side of the fault (Muirhead et al., 2016; Olive et al., 2014; Petit and Ebinger, 2000; Shillington et al., 
2020). In the case of the hanging-wall, this is a downward flexure that can result in intrabasinal faults accommodating additional slip to that imparted by regional extension alone (Muirhead et al., 2016). This additional flexural strain must therefore be accounted for when considering the slip rate of faults in Malawi (Sect. 3.2, main text).

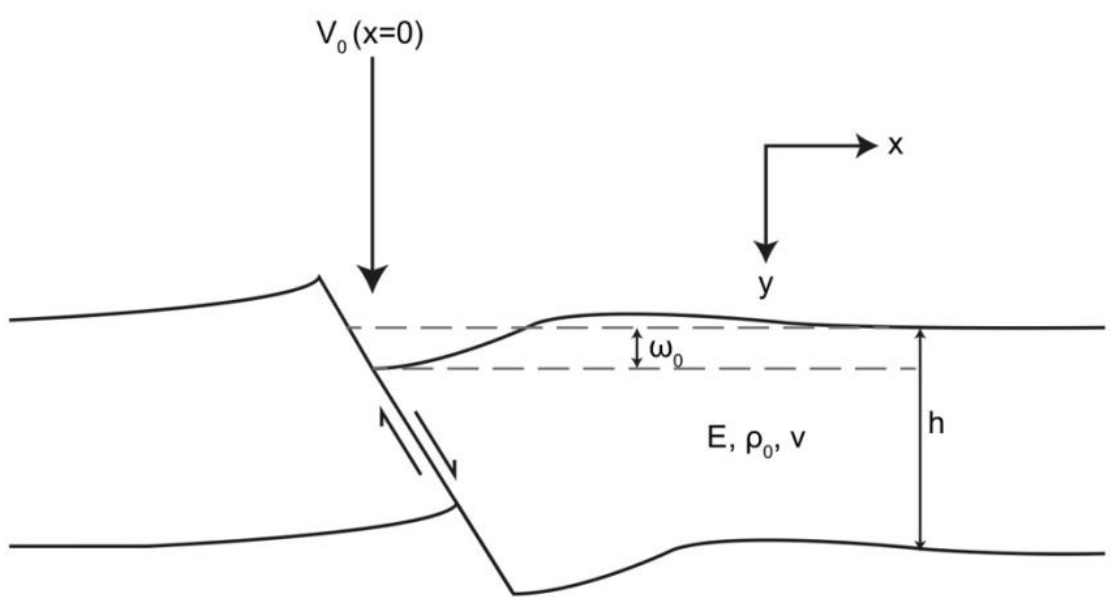

Figure A2: Set-up for hanging wall deflection equations. A vertical load $\left(V_{0}\right)$ is applied to the point where the hanging-wall intersects the surface (i.e., where $x=0)$ and where there is a maximum deflection $\left(\omega_{0}\right)$. The elastic thickness, Young's Modulus, density, and Poisson's ratio of the crust are represented by $h, E, \rho_{0}$, and $v$ respectively.

The influence of flexural strain on basement profiles across the Lake Malawi basins has been previously assessed (Shillington et al., 2020) using the Broken Plate model (Billings and Kattenhorn, 2005; Muirhead et al., 2016; Turcotte and Schubert, 1982) and we report here the values used to generate representative profiles across these basins in Fig. 4 in the main text. In addition, we apply the Broken Plate model to provide the first estimates of hanging-wall flexural strain in southern Malawi. Unlike in Lake Malawi, there is no subsurface data to validate the resulting profiles in this region, and there is additional complexity due to intrarift topography (e.g. Shire Horst, Kirk Range) and possible rift-widening events such as when the Lower Shire Basin was reactivated during East African Rifting (Castaing, 1991). Therefore, the purpose of these profiles is not to precisely model the across-rift basement geometry, but to estimate the range of hanging-wall flexural extension that may have occurred in southern Malawi given the uncertainty of each parameter we must test. This analysis is conducted only for the Makanjira, Zomba, and Lower Shire basins, as no intrarift faults have been identified in the Lengwe and Nsanje basins (Williams et al., 2021c).

The Broken Plate model calculates flexure by considering a vertical line-load at the point of maximum deflection (i.e., at the upper contact of the border fault hanging wall, Fig. S2). The deflection $(\omega)$ across a border fault hanging wall can then be estimated as: 
$\omega=\omega_{0} e^{\frac{-x}{\alpha}} \cos \left(\frac{x}{\alpha}\right)$

where $\omega_{0}$ is the maximum deflection, $x$ is the position along a hanging wall profile from the deflecting fault (Fig. S2), and $\alpha$ is:

620

$\alpha=\left[\frac{E h^{3}}{\left(3 \rho_{0} g\left(1-v^{2}\right)\right)}\right]^{\frac{1}{4}}$

where $E$ is Young's Modulus, $v$ is Poisson's ratio $(0.25), \mathrm{g}$ is acceleration due to gravity $\left(9.8 \mathrm{~m} / \mathrm{s}^{2}\right), h$ is the thickness of elastic crust, which is assumed here to be the equivalent to the thickness of Malawi's seismogenic layer. and $\rho 0$ is crustal density, for which the average crustal density $(2816 \mathrm{~kg} / \mathrm{m} 3)$ from a Malawi three layer model is used (Fagereng, 2013; Nyblade and Langston, 1995). Shillington et al., (2020) applied a value of $E$ ( $3 \pm 1.5 \mathrm{GPa})$ such that the hanging wall 625 deflection is restricted to a distance comparable to the actual width of Lake Malawi's basins, and we apply this value to south Malawi.

Table A2: Inputs and results of hanging-wall flexure analysis across Malawi. $\omega_{0}$; maximum hanging-wall deflection calculated from Eq. A3

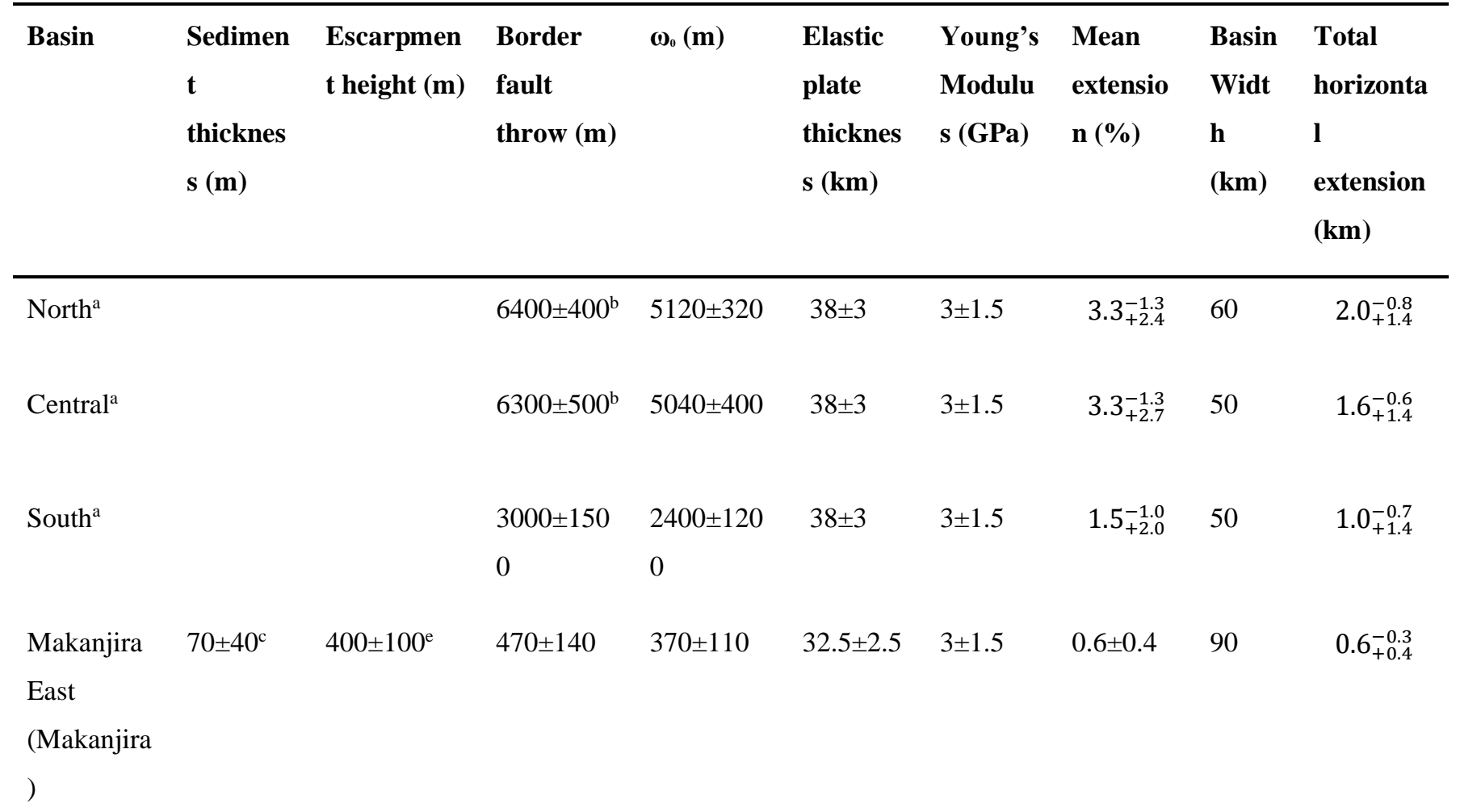


https://doi.org/10.5194/nhess-2021-306

Preprint. Discussion started: 16 November 2021

(c) Author(s) 2021. CC BY 4.0 License.

$\begin{array}{llllll}\text { Makanjira } \quad 70 \pm 40^{\mathrm{c}} & 850 \pm 150^{\mathrm{e}} \quad 920 \pm 190 \quad 740 \pm 150 & 32.5 \pm 2.5 & 3 \pm 1.5\end{array}$

West

(Chirobwe-

Ncheu)

$$
50 \pm 15^{\mathrm{d}}
$$

$300 \pm 100^{\mathrm{e}}$

$$
350 \pm 115
$$

$280 \pm 90$

$32.5 \pm 2.5 \quad 3 \pm 1.5$

$0.2 \pm 0.1$

60

$0.1_{+0.1}^{-0.05}$

Thyolo $65^{\mathrm{f}}$

$750 \pm 250^{\mathrm{g}}$

$815 \pm 250$

$650 \pm 200$

$32.5 \pm 2.5 \quad 3 \pm 1.5$

$0.5 \pm 0.2$

40

$0.2_{+0.2}^{-0.1}$

(EAR only)

Thyolo

$1815 \pm 250^{\mathrm{h}}$

$1450 \pm 200$

$32.5 \pm 2.5 \quad 3 \pm 1.5$

$1.0 \pm 0.2$

40

$0.4_{+0.4}^{-0.2}$

(EAR \&

Karoo)

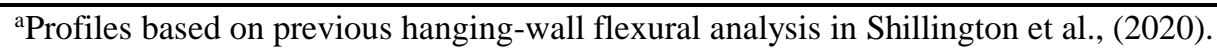

${ }^{b}$ Border fault throw estimates from Accardo et al., (2018).

${ }^{\mathrm{c}}$ Thickness of sediments in the Bwande-Liwawadze Valley based on electrical resistivity surveys (Walshaw, 1965) and borehole data. (Fig. A3; Bloomfield and Garson, 1965).

${ }^{\mathrm{d}}$ Thickness of sediments from borehole data within the Shire Plain (Fig. S3; Bloomfield and Garson, 1965).

635 eSee Laõ-Dávila et al., (2015). For the Zomba fault, topography associated with Chilwa Alkaline Province intrusion at the northern end of the fault is removed. Escarpment height from Chirbowe-Ncheu Fault also includes escarpment height of the Bilila-Mtakataka Fault.

${ }^{\mathrm{f}}$ See Wedmore et al., (2020b).

${ }^{\mathrm{g}}$ Maximum proven thickness boreholes in the Lower Shire Basin, though this is also comparable to other boreholes that did

640 penetrate basement (Fig. A3; Habgood et al., 1973).

${ }^{\text {h }}$ See text.

In Eq. A1, $\omega_{0}$ can be derived through the observation from real and modelled normal faults that the ratio $(r)$ of upthrow to downthrow along a normal fault is typically 0.2 (Muirhead et al., 2016). Therefore:

$645 \omega_{0}=B F_{\text {throw }}(1-r)$

where $B F_{\text {throw }}$ is border fault throw and is equivalent to the sum of the footwall escarpment height and hanging wall sediment thickness. There are significant uncertainties in estimating sediment thickness within southern Malawi, hence a range of values are used (Table A2). Uncertainty is highest in the Lower Shire Basin where few boreholes have penetrated basement 
(Fig. A3d) and there is ambiguity in whether the Thyolo fault was a bounding fault during Karoo-age (i.e. Mesozoic) rifting (Castaing, 1991; Habgood, 1963; Habgood et al., 1973; Wedmore et al., 2020b). We therefore model both scenarios. For the case where the Thyolo fault has only been active during East Africaan rifting, we estimate throw from combining an escarpment height of $750 \pm 250 \mathrm{~m}$ with a sediment thickness of $65 \mathrm{~m}$ (Table A2). This represents the maximum proven thickness of sediments in the Lower Shire (Fig A3d; Habgood et al., 1973), and although the true thickness of East African sediments in this basin may be greater, such a scenario would be accounted for in our Karoo rifting model. In this scenario, 655 we combine our EAR throw estimates for the Thyolo fault with the $1 \mathrm{~km}$ throw that is reported for Karoo bounding faults in the Lower Shire (Castaing, 1991).

Given a profile of hanging wall deflection, it is possible to derive the resulting flexural extensional strain $(\varepsilon)$ within a halfgraben (Billings and Kattenhorn, 2005; Muirhead et al., 2016)

$660 \varepsilon=-y\left(\frac{d^{2} \omega}{d x^{2}}\right)$

where $y$ is the vertical distance from the centre of the plate (downward is positive, Fig. A2). Following Muirhead et al., (2016) and Shillington et al., (2020), we report the flexural strain in terms of the average strain across each basin, and multiply this by basin width to get extension (Table A2). For the Makanjira graben, we calculate the mean strain from the contribution of each side of the graben over its $90 \mathrm{~km}$ width (i.e., for the Chirobwe Ncheu and Makanjira faults, Fig A3,

665 Table S2).

Results of this analysis are shown in Figs. 4 (Lake Malawi basins), A3 (south Malawi basins), and Table A2. These demonstrate that regardless of the simplifications, uncertainties and assumptions in this analysis, hanging-wall flexure in southern Malawi is negligible (strains <1\%) compared to the Lake Malawi basins. Furthermore, unlike the Lake Malawi basins, the flexural profiles in southern Malawi do not match the observed topography (Fig. A3), which further indicates minimal flexural extension in these basins. This result reflects the significant differences in total rift extension between the South Basin and Makanjira Graben and resulting reduction in border fault throw between these basins (Table A2). We therefore do not consider hanging-wall flexure further when considering the slip rate of intrarift sources in southern Malawi (Sect. 3.2, main text). 
(a)

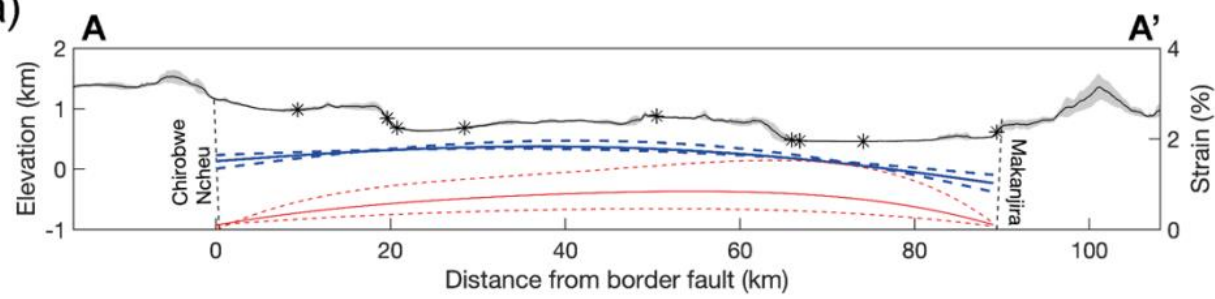

(b)

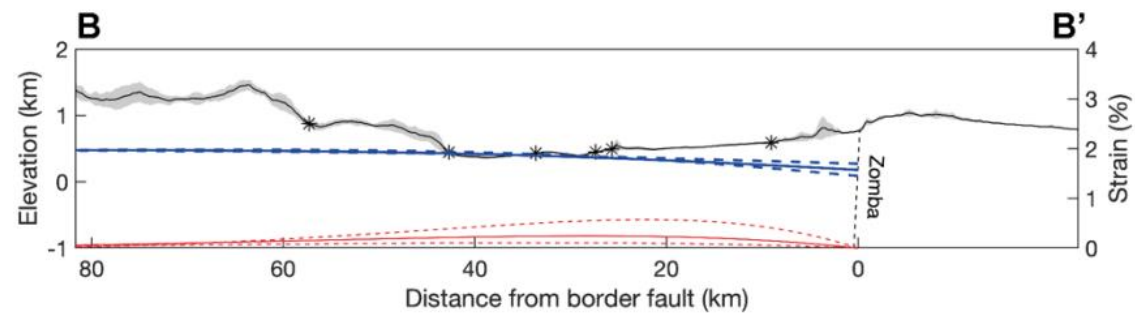

(c)

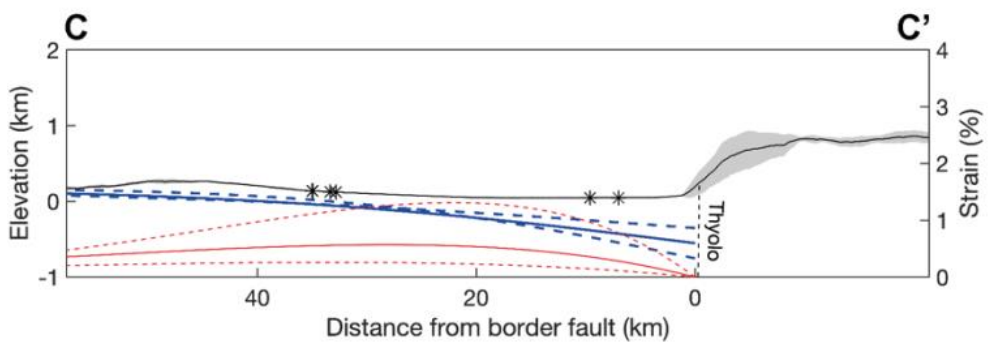

(d)

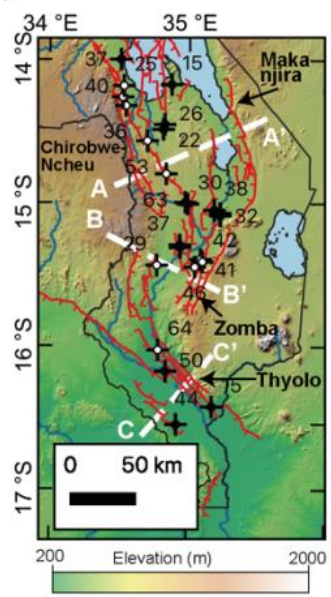

Borehole, basement

not encountered,

depth in $\mathrm{m}$

675

Figure A3: Modelled hanging-wall flexural profiles and horizontal extensional strain in southern Malawi. Profiles have 6x vertical exaggeration. Calculated following broken plate model (Fig. A2; Billings and Kattenhorn, 2005; Muirhead et al., 2016; Turcotte and Schubert, 1982) and parameters listed in Table A2. Solid hanging-wall profile and strain line indicates median estimates, dashed line indicates maximum and minimum estimates. (c) Assumes a profile where the Thyolo fault has only been active during EAR rifting. Solid black line and gray shading represents mean and one standard deviation topography from TanDEM-X 12 m DEM in $10 \mathrm{~km}$ swath centred on lines shown in (d) (Schwanghart and Scherler, 2014). Labelled faults indicate border faults. In (d)), the location and depth to basement in boreholes in south Malawi are also shown (Bloomfield and Garson, 1965; Habgood, 1963; Habgood et al., 1973; Walshaw, 1965; Walter, 1972). Map underlain by $30 \mathrm{~m}$ resolution Shuttle Radar Topographic Mission digital elevation model.

The higher hanging-wall flexural strain in the Lake Malawi basins ( 1-3\%, Table A2) suggest that the hanging-wall flexural extension correction factor $\left(c_{h w f}\right)$ should be applied when estimate slip rates of their intrarift sources in the MSSD (Eqs. 2 and 3 in the main text). This factor is derived by combining a basin's hanging-wall flexural extension (Table S2 and S3) with the total cumulative extension its intrarift faults ( $T_{i f-e x t}$, eq. 3 in the main text). However, this parameter is poorly constrained apart for intrarift sources, and so we make the following assumptions when deriving $T_{i f-e x t}$ : 
- For intrarift faults in the North Basin, the total observed cumulative extension is $2 \pm 0.4 \mathrm{~km}$, however, it is estimated that $30 \%$ of the extension in the basin may be accommodated by faults below the resolution of the seismic survey (Shillington et al., 2020). Therefore, the total extension of intrarift faults under Lake Malawi's North Basin is estimated to be $2.6 \pm 0.5 \mathrm{~km}$. There are three onshore intrarift fault/multifault sources in the North Basin (Fig. 2a). If it assumed that they have accommodated a similar amount of extension as the four offshore fault/mulitfault sources, then their total extension is $1.5 \pm 0.3 \mathrm{~km}$, and hence $T_{\text {if-ext }}$, for the North Basin is $4.1 \pm 0.8 \mathrm{~km}$.

- No estimates exist for the total observed cumulative extension of intrarift faults under Lake Malawi in the Central and South Basins. However, we note that the Central Basin's age, and flexural and total extension (7.0 vs 6.3 km; Scholz et al., 2020) are very similar to the North Basin. We therefore assume that the Central Basin's sub-lacustrine intrarift faults have accommodated the same amount of extension as the North Basin's, and then apply the same workflow to calculate $T_{\text {if-ext }}$, although in this case there are two and ten onshore and offshore intrarift fault/multifault sources respectively (Table A3).

- Flexural and total extension estimates in the South Basin are approximately $50 \%$ of the values for the Central and North Basins ( 6-7 km vs 3.7 km; Scholz et al., 2020). We adjust the total extension of sub-lacustrine intrarift faults in the South Basin accordingly and note there are seven and eight onshore and offshore intrarift fault/multifault sources respectively (Table A3).

- Within the uncertainty of the hanging-wall flexural profiles across the Lake Malawi basins, it is possible that all the intrarift fault displacement can be accounted for by hanging-wall flexure (i.e., $c_{h w f} \rightarrow \infty$ ). However, we do not consider this a realistic scenario since other factors (e.g., structural inheritance) can cause intrarift faults to accommodate regional rift extension prior to significant flexural extension (Kolawole et al., 2021b; Wedmore et al., 2020a) and so $c_{h w f}$ is truncated at values $>5$.

Table A3: Values used to derive the hanging-wall correction factor ( $c_{h w f}$, Eq. 3) in slip rate calculations (Eq. 2) for intrarift sources in the North, South, and Central basins. Workflow is discussed in Appendix A text.

\begin{tabular}{|c|c|c|c|c|c|c|}
\hline Basin & $\begin{array}{l}\text { Cumulative } \\
\text { lake fault } \\
\text { extension (km) }\end{array}$ & $\begin{array}{l}\text { Subseismic } \\
\text { correction } \\
\text { (m) }\end{array}$ & $\begin{array}{l}\text { Onshore } \\
\text { fault } \\
\text { extension }\end{array}$ & $\begin{array}{l}\text { Total } \\
\text { intrarift } \\
\text { fault } \\
\text { extension }\end{array}$ & $\begin{array}{l}\text { Hanging-wall } \\
\text { flexure } \\
\text { extension } \\
(\mathrm{km})\end{array}$ & $\begin{array}{l}\text { Hanging-wall } \\
\text { flexure } \\
\text { correction } \\
\text { factor }\left(c_{h w f}\right)\end{array}$ \\
\hline $\begin{array}{l}\text { North } \\
\text { Basin }\end{array}$ & $2 \pm 0.4$ & $2.6 \pm 0.5$ & $1.5 \pm 0.3$ & $4.1 \pm 0.8$ & $2.0_{+1.4}^{-0.8}$ & $2.0_{+3.0}^{-0.7}$ \\
\hline Central & $2 \pm 0.4$ & $2.6 \pm 0.5$ & $0.4 \pm 0.1$ & $3.0 \pm 0.6$ & $1.6_{+1.4}^{-0.6}$ & $2.2_{+2.8}^{-0.9}$ \\
\hline
\end{tabular}


Basin
South
$1 \pm 0.4$
$1.3 \pm 0.5$
$0.9 \pm 0.4$
$2.2 \pm 0.9$
$1.0_{+1.4}^{-0.7}$
$1.9_{+3.1}^{-0.8}$

Basin

\section{Data availability}

The Malawi Seismogenic Source Database (MSSD) can be accessed through Github at https://github.com/LukeWedmore/malawi_seismogenic_source_database/tree/v1.0 and through Zenodo at: https://zenodo.org/record/5599617\#.YXhT2i0Rpz8: The Malawi Active Fault Database can be accessed at

720 https://github.com/LukeWedmore/malawi_active_fault_database/tree/v1.0 and https://zenodo.org/record/5507190\#.YWuk2C0RpB2.

\section{Author Contributions}

Conceptualization: JW, LNJW, AF, and JB. Data curation: JW and LNJW. Methodology: all authors. Formal analysis: JW, LNJW, DS, CS, and LJMW. Funding acquisition: JB, AF, and MW. Writing - original draft preparation: JW. Writing review and editing: all authors.

\section{Competing interests}

The authors declare that they have no conflict of interest.

\section{Acknowledgements}

This work is supported by the EPSRC-Global Challenges Research Fund PREPARE (EP/P028233/1) and SAFERPREPARED (part of the 'Innovative data services for aquaculture, seismic resilience and drought adaptation in East Africa' grant; EP/T015462/1) projects.

\section{References}

Accardo, N. J., Shillington, D. J., Gaherty, J. B., Scholz, C. A., Nyblade, A. A., Chindandali, P. R. N., Kamihanda, G., McCartney, T., Wood, D. and Wambura Ferdinand, R.: Constraints on Rift Basin Structure and Border Fault Growth in the 735 Northern Malawi Rift From 3-D Seismic Refraction Imaging, J. Geophys. Res. Solid Earth, 123(11), 3-10,10,25, 
doi:10.1029/2018JB016504, 2018.

Accardo, N. J., Gaherty, J. B., Shillington, D. J., Hopper, E., Nyblade, A. A., Ebinger, C. J., Scholz, C. A., Chindandali, P. R. N., Wambura-Ferdinand, R., Mbogoni, G., Russell, J. B., Holtzman, B. K., Havlin, C. and Class, C.: Thermochemical Modification of the Upper Mantle Beneath the Northern Malawi Rift Constrained From Shear Velocity Imaging, Geochemistry, Geophys. Geosystems, 21(6), 1-19, doi:10.1029/2019GC008843, 2020.

Acocella, V., Faccenna, C., Funiciello, R. and Rossetti, F.: Sand-box modelling of basement-controlled transfer zones in extensional domains, Terra Nov., 11(4), 149-156, doi:10.1046/j.1365-3121.1999.00238.x, 1999.

Agostini, A., Bonini, M., Corti, G., Sani, F. and Mazzarini, F.: Fault architecture in the Main Ethiopian Rift and comparison with experimental models: Implications for rift evolution and Nubia-Somalia kinematics, Earth Planet. Sci. Lett., 301(3-4), 479-492, doi:10.1016/j.eps1.2010.11.024, 2011.

Ambraseys, N. N.: The Rukuwa Earthquake of 13 December 1910 In East-Africa, Terra Nov., 3(2), 202-211, doi:10.1111/j.1365-3121.1991.tb00873.x, 1991.

Ayele, A. and Kulhanek, O.: Reassessment of source parameters for three major earthquakes in the East African rift system from historical seismograms and bulletins, Ann. di Geofis., 43(1), 81-94, doi:10.4401/ag-3627, 2000.

Baize, S., Nurminen, F., Sarmiento, A., Dawson, T., Takao, M., Scotti, O., Azuma, T., Boncio, P., Champenois, J., Cinti, F. R., Civico, R., Costa, C., Guerrieri, L., Marti, E., McCalpin, J., Okumura, K. and Villamor, P.: A worldwide and unified database of surface ruptures (SURE) for fault displacement hazard analyses, Seismol. Res. Lett., 91(1), 499-520, doi:10.1785/0220190144, 2019.

Basili, R., Valensise, G., Vannoli, P., Burrato, P., Fracassi, U., Mariano, S., Tiberti, M. M. and Boschi, E.: The Database of Individual Seismogenic Sources (DISS), version 3: Summarizing 20 years of research on Italy's earthquake geology, Tectonophysics, 453(1-4), 20-43, doi:10.1016/j.tecto.2007.04.014, 2008.

Beanland, S. and Berryman, K. R.: Style and episodicity of late quaternary activity on the pisa-grandview fault zone, Central Otago, New Zealand, New Zeal. J. Geol. Geophys., 32(4), 451-461, doi:10.1080/00288306.1989.10427553, 1989.

Beauval, C., Marinière, J., Yepes, H., Audin, L., Nocquet, J. M., Alvarado, A., Baize, S., Aguilar, J., Singaucho, J. C. and

Jomard, H.: A new seismic hazard model for ecuador, Bull. Seismol. Soc. Am., 108(3), 1443-1464, doi:10.1785/0120170259, 2018.

Bendick, R., Bilham, R., Freymueller, J., Larson, K. and Yin, G.: Geodetic evidence for a low slip rate in the Altyn Tagh fault system, Nature, 404(6773), 69-72, doi:10.1038/35003555, 2000.

Bhat, H. S., Olives, M., Dmowska, R. and Rice, J. R.: Role of fault branches in earthquake rupture dynamics, J. Geophys. 765 Res. Solid Earth, 112(11), 1-16, doi:10.1029/2007JB005027, 2007.

Biasi, G. P. and Wesnousky, S. G.: Steps and gaps in ground ruptures: Empirical bounds on rupture propagation, Bull. Seismol. Soc. Am., 106(3), 1110-1124, doi:10.1785/0120150175, 2016.

Biasi, G. P. and Wesnousky, S. G.: Bends and Ends of Surface Ruptures, Bull. Seismol. Soc. Am., 107(6), 2543-2560 [online] Available from: http://dx.doi.org/10.1785/0120160292, 2017. 

2009 Karonga earthquakes, Malawi, Geophys. Res. Lett., 37(11), doi:10.1029/2010GL043179, 2010.

Billings, S. E. and Kattenhorn, S. A.: The great thickness debate: Ice shell thickness models for Europa and comparisons with estimates based on flexure at ridges, Icarus, 177(2), 397-412, doi:10.1016/j.icarus.2005.03.013, 2005.

Bird, P. and Liu, Z.: Seismic hazard inferred from tectonics: California, Seismol. Res. Lett., 78(1), 37-48, doi:10.1785/gssrl.78.1.37, 2007.

Bloomfield, K. and Garson, M. S.: The Geology of the Kirk Range-Lisungwe Valley Area, Bull. Geol. Surv. Malawi, 17, 1965.

Bommer, J. J. and Scherbaum, F.: The use and misuse of logic trees in probabilistic seismic hazard analysis, Earthq. Spectra, 24(4), 997-1009, doi:10.1193/1.2977755, 2008.

780 Bormann, J. M., Hammond, W. C., Kreemer, C. and Blewitt, G.: Accommodation of missing shear strain in the Central Walker Lane, western North America: Constraints from dense GPS measurements, Earth Planet. Sci. Lett., 440, 169-177, doi:10.1016/j.eps1.2016.01.015, 2016.

Brown, A. R.: Structural Interpretation, in Interpretation of Three-Dimensional Seismic Data, Seventh edition, pp. 61-102, Society of Exploration Geophysicists and American Association of Petroleum Geologists., 2011.

785 Castaing, C.: Post-Pan-African tectonic evolution of South Malawi in relation to the Karroo and recent East African rift systems, Tectonophysics, 191(1-2), 55-73, doi:10.1016/0040-1951(91)90232-H, 1991.

Chisenga, C., Dulanya, Z. and Jianguo, Y.: The structural re-interpretation of the Lower Shire Basin in the Southern Malawi rift using gravity data, J. African Earth Sci., 149(September), 280-290, doi:10.1016/j.jafrearsci.2018.08.013, 2019.

Christophersen, A., Litchfield, N., Berryman, K., Thomas, R., Basili, R., Wallace, L., Ries, W., Hayes, G. P., Haller, K. M.,

790 Yoshioka, T., Koehler, R. D., Clark, D., Wolfson-Schwehr, M., Boettcher, M. S., Villamor, P., Horspool, N., Ornthammarath, T., Zuñiga, R., Langridge, R. M., Stirling, M. W., Goded, T., Costa, C. and Yeats, R.: Development of the Global Earthquake Model's neotectonic fault database, Nat. Hazards, 79(1), 111-135, doi:10.1007/s11069-015-1831-6, 2015.

Clemons, T. E. and Bradley, E. L.: Nonparametric measure of the overlapping coefficient, Comput. Stat. Data Anal., 34(1), 795 51-61, doi:10.1016/S0167-9473(99)00074-2, 2000.

Contreras, J., Anders, M. H. and Scholz, C. H.: Growth of a normal fault system: Observations from the Lake Malawi basin of the east African rift, J. Struct. Geol., 22(2), 159-168, doi:10.1016/S0191-8141(99)00157-1, 2000.

Cornell, C. A.: Engineering seismic risk analysis, Bull. Seismol. Soc. Am., 58(5), 1583-1606, doi:http://dx.doi.org/10.1016/0167-6105(83)90143-5, 1968.

800 Cowie, P. A. and Roberts, G. P.: Constraining slip rates and spacings for active normal faults, J. Struct. Geol., 23(12), 19011915, doi:10.1016/S0191-8141(01)00036-0, 2001.

Cowie, P. A., Roberts, G. P., Bull, J. M. and Visini, F.: Relationships between fault geometry, slip rate variability and earthquake recurrence in extensional settings, Geophys. J. Int., 189(1), 143-160, doi:10.1111/j.1365-246X.2012.05378.x, 
2012.

Cox, S. C., Stirling, M. W., Herman, F., Gerstenberger, M. and Ristau, J.: Potentially active faults in the rapidly eroding landscape adjacent to the Alpine Fault, central Southern Alps, New Zealand, Tectonics, 31(2), doi:10.1029/2011TC003038, 2012.

Craig, T. J. and Jackson, J. A.: Variations in the Seismogenic Thickness of East Africa, J. Geophys. Res. Solid Earth, 126(3), 1-15, doi:10.1029/2020JB020754, 2021.

810 Cramer, C. H., Petersen, M. D. and Reichle, M. S.: A Monte Carlo approach in estimating uncertainty for a seismic hazard assessment of Los Angeles, Ventura, and Orange Counties, California, Bull. Seismol. Soc. Am., 86(6), 1681-1691, 1996.

Das, S. and Scholz, C. H.: Why large earthquakes do not nucleate at shallow depths, Nature, 305(5935), 621-623, 1983.

Dawson, S. M., Laó-Dávila, D. A., Atekwana, E. A. and Abdelsalam, M. G.: The influence of the Precambrian Mughese Shear Zone structures on strain accommodation in the northern Malawi Rift, Tectonophysics, 722, 53-68, doi:10.1016/j.tecto.2017.10.010, 2018.

Delvaux, D. and Barth, A.: African stress pattern from formal inversion of focal mechanism data, Tectonophysics, 482(1-4), 105-128, doi:10.1016/j.tecto.2009.05.009, 2010.

Delvaux, D., Mulumba, J. L., Sebagenzi, M. N. S., Bondo, S. F., Kervyn, F. and Havenith, H. B.: Seismic hazard assessment of the Kivu rift segment based on a new seismotectonic zonation model (western branch, East African Rift system), J.

African Earth Sci., 134, 831-855, doi:10.1016/j.jafrearsci.2016.10.004, 2017.

Van Dissen, R., Seebeck, H., Litchfield, N., Barnes, P., Nicol, A., Langridge, R., Barrell, D., Villamor, P., Ellis, S. and Rattenbury, M.: Development of the New Zealand Community Fault Model-version 1.0, 2021.

Dolan, J. F. and Meade, B. J.: A Comparison of Geodetic and Geologic Rates Prior to Large Strike-Slip Earthquakes: A Diversity of Earthquake-Cycle Behaviors?, Geochemistry, Geophys. Geosystems, 18(12), 4426-4436, doi:10.1002/2017GC007014, 2017.

DuRoss, C. B., Personius, S. F., Crone, A. J., Olig, S. S., Hylland, M. D., Lund, W. R. and Schwartz, D. P.: Fault segmentation: New concepts from the Wasatch Fault Zone, Utah, USA, J. Geophys. Res. Solid Earth, 121(2), 1131-1157, doi:10.1002/2015JB012519, 2016.

DuRoss, C. B., Gold, R. D., Briggs, R. W., Delano, J. E., Ostenaa, D. A., Zellman, M. S., Cholewinski, N., Wittke, S. J. and

830 Mahan, S. A.: Holocene earthquake history and slip rate of the southern Teton fault, Wyoming, USA, Bull. Geol. Soc. Am., 132(7-8), 1566-1586, doi:10.1130/B35363.1, 2020.

Ebinger, C. J.: Tectonic development of the western branch of the East African rift system, Geol. Soc. Am. Bull., 101(7), 885-903, doi:10.1130/0016-7606(1989)101<0885:TDOTWB>2.3.CO;2, 1989.

Ebinger, C. J., Oliva, S. J., Pham, T. Q., Peterson, K., Chindandali, P., Illsley-Kemp, F., Drooff, C., Shillington, D. J., 835 Accardo, N. J., Gallacher, R. J., Gaherty, J., Nyblade, A. A. and Mulibo, G.: Kinematics of Active Deformation in the Malawi Rift and Rungwe Volcanic Province, Africa, Geochemistry, Geophys. Geosystems, 20(8), 3928-3951, doi:10.1029/2019GC008354, 2019. 
Fagereng, Å.: Fault segmentation, deep rift earthquakes and crustal rheology: Insights from the 2009 Karonga sequence and seismicity in the Rukwa-Malawi rift zone, Tectonophysics, 601, 216-225, doi:10.1016/j.tecto.2013.05.012, 2013.

Fagereng, Å. and Biggs, J.: New perspectives on 'geological strain rates" calculated from both naturally deformed and actively deforming rocks,' J. Struct. Geol., 125, 100-110, doi:10.1016/j.jsg.2018.10.004, 2019.

Faleide, T. S., Braathen, A., Lecomte, I., Mulrooney, M. J., Midtkandal, I., Bugge, A. J. and Planke, S.: Impacts of seismic resolution on fault interpretation: Insights from seismic modelling, Tectonophysics, 816, 229008, doi:10.1016/j.tecto.2021.229008, 2021.

845 Faure Walker, J., Boncio, P., Pace, B., Roberts, G., Benedetti, L., Scotti, O., Visini, F. and Peruzza, L.: Fault2SHA Central Apennines database and structuring active fault data for seismic hazard assessment, Sci. Data, 8(1), 1-20, doi:10.1038/s41597-021-00868-0, 2021.

Fenton, C. H. and Bommer, J. J.: The Mw7 Machaze, Mozambique, earthquake of 23 February 2006, Seismol. Res. Lett., 77(4), 426-439, doi:10.1785/gssrl.77.4.426, 2006.

850 Flannery, J. W. and Rosendahl, B. R.: The seismic stratigraphy of Lake Malawi, Africa: implications for interpreting geological processes in lacustrine rifts, J. African Earth Sci., 10(3), 519-548, doi:10.1016/0899-5362(90)90104-M, 1990.

Fletcher, J. M., Teran, O. J., Rockwell, T. K., Oskin, M. E., Hudnut, K. W., Mueller, K. J., Spelz, R. M., Akciz, S. O., Masana, E., Faneros, G., Fielding, E. J., Leprince, S., Morelan, A. E., Stock, J., Lynch, D. K., Elliott, A. J., Gold, P., LiuZeng, J., González-Ortega, A., Hinojosa-Corona, A. and González-García, J.: Assembly of a large earthquake from a complex fault system: Surface rupture kinematics of the 4 April 2010 El Mayor-Cucapah (Mexico) M w 7.2 earthquake, Geosphere, 10(4), 797-827, doi:10.1130/GES00933.1, 2014.

Gaherty, J. B., Zheng, W., Shillington, D. J., Pritchard, M. E., Henderson, S. T., Chindandali, P. R. N., Mdala, H., Shuler, A., Lindsey, N., Oliva, S. J., Nooner, S., Scholz, C. A., Schaff, D., Ekström, G. and Nettles, M.: Faulting processes during early-stage rifting: Seismic and geodetic analysis of the 2009-2010 Northern Malawi earthquake sequence, Geophys. J. Int., 217(3), 1767-1782, doi:10.1093/gji/ggz119, 2019.

Geist, E. L. and Parsons, T.: Distribution of Earthquakes on a Branching Fault System Using Integer Programming and Greedy-Sequential Methods, Geochemistry, Geophys. Geosystems, 21(9), 1-22, doi:10.1029/2020GC008964, 2020.

Gerstenberger, M. C., Marzocchi, W., Allen, T., Pagani, M., Adams, J., Danciu, L., Field, E. H., Fujiwara, H., Luco, N., Ma, K. F., Meletti, C. and Petersen, M. D.: Probabilistic Seismic Hazard Analysis at Regional and National Scales: State of the

Art and Future Challenges, Rev. Geophys., 58(2), e2019RG000653, doi:10.1029/2019RG000653, 2020.

Giordano, N., De Risi, R., Voyagaki, E., Kloukinas, P., Novelli, V., Kafodya, I., Ngoma, I., Goda, K. and Macdonald, J.: Seismic fragility models for typical non-engineered URM residential buildings in Malawi, in Structures, vol. 32, pp. 22662278, Elsevier., 2021.

Goda, K., Gibson, E. D., Smith, H. R., Biggs, J. and Hodge, M.: Seismic risk assessment of urban and rural settlements around lake malawi, Front. Built Environ., 2, doi:10.3389/fbuil.2016.00030, 2016.

Goda, K., Novelli, V., De Risi, R., Kloukinas, P., Giordano, N., Macdonald, J., Kafodya, I., Ngoma, I. and Voyagaki, E.: 
Scenario-based earthquake risk assessment for central-southern Malawi: The case of the Bilila-Mtakataka Fault, Int. J. Disaster Risk Reduct., 102655, doi:https://doi.org/10.1016/j.ijdrr.2021.102655, 2021.

Gómez-Novell, O., García-Mayordomo, J., Ortuño, M., Masana, E. and Chartier, T.: Fault System-Based Probabilistic

875 Seismic Hazard Assessment of a Moderate Seismicity Region: The Eastern Betics Shear Zone (SE Spain), Front. Earth Sci., 8(December), doi:10.3389/feart.2020.579398, 2020.

Gupta, H. K. and Malomo, S.: The Malawi earthquake of March 10, 1989: A report of the macroseismic survey, Seismol. Res. Lett., 66(1), 20-27, doi:10.1016/0040-1951(92)90018-2, 1995.

Gupta, S., Cowie, P. A., Dawers, N. H. and Underhill, J. R.: A mechanism to explain rift-basin subsidence and stratigraphic patterns through fault-array evolution, Geology, 26(7), 595-598, doi:10.1130/00917613(1998)026<0595:AMTERB>2.3.CO, 1998.

Habgood, F.: The geology of the country west of the Shire River between Chikwawa and Chiromo, Bull. Geol. Surv. Malawi, 14, 1963.

Habgood, F., Holt, D. N. and Walshaw, R. D.: The geology of the Thyolo Area, Bull. Geol. Surv. Malawi, 22, 1973.

Hamiel, Y., Baer, G., Kalindekafe, L., Dombola, K. and Chindandali, P.: Seismic and aseismic slip evolution and deformation associated with the 2009-2010 northern Malawi earthquake swarm, East African Rift, Geophys. J. Int., 191(3), 898-908, doi:10.1111/j.1365-246X.2012.05673.x, 2012.

Hanks, T. C. and Bakun, W. H.: A bilinear source-scaling model for M-log a observations of continental earthquakes, Bull. Seismol. Soc. Am., 92(5), 1841-1846, doi:10.1785/0120010148, 2002.

890 Hellebrekers, N., Niemeijer, A. R., Fagereng, Å., Manda, B. and Mvula, R. L. S.: Lower crustal earthquakes in the East African Rift System: Insights from frictional properties of rock samples from the Malawi rift, Tectonophysics, 767, 228167, doi:10.1016/j.tecto.2019.228167, 2019.

Helmstetter, A. and Werner, M. J.: Adaptive spatiotemporal smoothing of seismicity for long-term earthquake forecasts in California, Bull. Seismol. Soc. Am., 102(6), 2518-2529, doi:10.1785/0120120062, 2012.

895 Henry, C. and Das, S.: Aftershock zones of large shallow earthquakes: Fault dimensions, aftershock area expansion and scaling relations, Geophys. J. Int., 147(2), 272-293, doi:10.1046/j.1365-246X.2001.00522.x, 2001.

Hetland, E. A. and Hager, B. H.: Interseismic strain accumulation: Spin-up, cycle invariance, and irregular rupture sequences, Geochemistry, Geophys. Geosystems, 7(5), doi:10.1029/2005GC001087, 2006.

Hodge, M., Biggs, J., Goda, K. and Aspinall, W.: Assessing infrequent large earthquakes using geomorphology and geodesy: the Malawi Rift, Nat. Hazards, 76(3), 1781-1806, doi:10.1007/s11069-014-1572-y, 2015.

Hodge, M., Fagereng, A., Biggs, J. and Mdala, H.: Controls on Early-Rift Geometry: New Perspectives From the BililaMtakataka Fault, Malawi, Geophys. Res. Lett., 45(9), 3896-3905, doi:10.1029/2018GL077343, 2018a.

Hodge, M., Fagereng, A. and Biggs, J.: The Role of Coseismic Coulomb Stress Changes in Shaping the Hard Link Between Normal Fault Segments, J. Geophys. Res. Solid Earth, 123(1), 797-814, doi:10.1002/2017JB014927, 2018 b. 
morphology (SPARTA): Application to normal faults in southern Malawi, Solid Earth, 10(1), 27-57, doi:10.5194/se-10-272019, 2019.

Hodge, M., Biggs, J., Fagereng, Mdala, H., Wedmore, L. N. J. and Williams, J. N.: Evidence From High-Resolution Topography for Multiple Earthquakes on High Slip-to-Length Fault Scarps: The Bilila-Mtakataka Fault, Malawi, Tectonics,

910 39(2), e2019TC005933, doi:10.1029/2019TC005933, 2020.

Hopper, E., Gaherty, J. B., Shillington, D. J., Accardo, N. J., Nyblade, A. A., Holtzman, B. K., Havlin, C., Scholz, C. A., Chindandali, P. R. N., Ferdinand, R. W., Mulibo, G. D. and Mbogoni, G.: Preferential localized thinning of lithospheric mantle in the melt-poor Malawi Rift, Nat. Geosci., 13(8), 584-589, doi:10.1038/s41561-020-0609-y, 2020.

Inman, H. F. and Bradley Jr, E. L.: The overlapping coefficient as a measure of agreement between probability distributions

915 and point estimation of the overlap of two normal densities, Commun. Stat. Methods, 18(10), 3851-3874, 1989.

Jackson, J. and Blenkinsop, T.: The Malaŵi Earthquake of March 10, 1989: Deep faulting within the East African Rift System, Tectonics, 12(5), 1131-1139, doi:10.1029/93TC01064, 1993.

Jackson, J. and Blenkinsop, T.: The Bilila-Mtakataka fault in Malawi: an active, 100-km long, normal fault segment in thick seismogenic crust, Tectonics, 16(1), 137-150, doi:10.1029/96TC02494, 1997.

920 Kagan, Y. Y., Jackson, D. D. and Geller, R. J.: Characteristic earthquake model, 1884-2011, R.I.P., Seismol. Res. Lett., 83(6), 951-953, doi:10.1785/0220120107, 2012.

Kanamori, H. and Anderson, D. L.: Theoretical basis of some empirical relations in seismology, Bull. Seismol. Soc. Am., 65(5), 1073-1095, 1975.

Kervyn, F., Ayub, S., Kajara, R., Kanza, E. and Temu, B.: Evidence of recent faulting in the Rukwa rift (West Tanzania) based on radar interferometric DEMs, J. African Earth Sci., 44(2), 151-168, doi:10.1016/j.jafrearsci.2005.10.008, 2006.

King, G. C. P.: Speculations on the geometry of the initiation and termination processes of earthquake rupture and its relation to morphology and geological structure, Pure Appl. Geophys. PAGEOPH, 124(3), 567-585, doi:10.1007/BF00877216, 1986.

Kolawole, F., Atekwana, E. A., Laó-Dávila, D. A., Abdelsalam, M. G., Chindandali, P. R., Salima, J. and Kalindekafe, L.:

930 Active Deformation of Malawi Rift's North Basin Hinge Zone Modulated by Reactivation of Preexisting Precambrian Shear Zone Fabric, Tectonics, 37(3), 683-704, doi:10.1002/2017TC004628, 2018a.

Kolawole, F., Atekwana, E. A., Laó-Dávila, D. A., Abdelsalam, M. G., Chindandali, P. R., Salima, J. and Kalindekafe, L.: High-resolution electrical resistivity and aeromagnetic imaging reveal the causative fault of the 2009 Mw 6.0 Karonga, Malawi earthquake, Geophys. J. Int., 213(2), 1412-1425, doi:10.1093/gji/ggy066, $2018 \mathrm{~b}$.

935 Kolawole, F., Firkins, M. C., Al Wahaibi, T. S., Atekwana, E. A. and Soreghan, M. J.: Rift interaction zones and the stages of rift linkage in active segmented continental rift systems, Basin Res., doi:10.1111/bre.12592, 2021a.

Kolawole, F., Phillips, T. B., Atekwana, E. A. and Jackson, C. A. L.: Structural Inheritance Controls Strain Distribution During Early Continental Rifting, Rukwa Rift, Front. Earth Sci., 9(August), 1-14, doi:10.3389/feart.2021.707869, 2021 b.

Laõ-Dávila, D. A., Al-Salmi, H. S., Abdelsalam, M. G. and Atekwana, E. A.: Hierarchical segmentation of the Malawi Rift: 
940 The influence of inherited lithospheric heterogeneity and kinematics in the evolution of continental rifts, Tectonics, 34(12), 2399-2417, doi:10.1002/2015TC003953, 2015.

Leonard, M.: Earthquake fault scaling: Self-consistent relating of rupture length, width, average displacement, and moment release, Bull. Seismol. Soc. Am., 100(5 A), 1971-1988, doi:10.1785/0120090189, 2010.

Litchfield, N. J., Van Dissen, R., Sutherland, R., Barnes, P. M., Cox, S. C., Norris, R., Beavan, R. J., Langridge, R.,

Villamor, P., Berryman, K., Stirling, M., Nicol, A., Nodder, S., Lamarche, G., Barrell, D. J. A., Pettinga, J. R., Little, T., Pondard, N., Mountjoy, J. J. and Clark, K.: A model of active faulting in New Zealand, New Zeal. J. Geol. Geophys., 57(1), 32-56, doi:10.1080/00288306.2013.854256, 2014.

Litchfield, N. J., Villamor, P., van Dissen, R. J., Nicol, A., Barnes, P. M., Barrell, D. J. A., Pettinga, J. R., Langridge, R. M., Little, T. A., Mountjoy, J. J., Ries, W. F., Rowland, J., Fenton, C., Stirling, M. W., Kearse, J., Berryman, K. R., Cochran, U. 950 A., Clark, K. J., Hemphill-Haley, M., Khajavi, N., Jones, K. E., Archibald, G., Upton, P., Asher, C., Benson, A., Cox, S. C., Gasston, C., Hale, D., Hall, B., Hatem, A. E., Heron, D. W., Howarth, J., Kane, T. J., Lamarche, G., Lawson, S., Lukovic, B., McColl, S. T., Madugo, C., Manousakis, J., Noble, D., Pedley, K., Sauer, K., Stahl, T., Strong, D. T., Townsend, D. B., Toy, V., Williams, J., Woelz, S. and Zinke, R.: Surface rupture of multiple crustal faults in the 2016 Mw 7.8 Kaikōura, New Zealand, earthquake, Bull. Seismol. Soc. Am., 108(3B), 1496-1520, doi:10.1785/0120170300, 2018.

955 Macheyeki, A. S., Mdala, H., Chapola, L. S., Manhiça, V. J., Chisambi, J., Feitio, P., Ayele, A., Barongo, J., Ferdinand, R. W., Ogubazghi, G., Goitom, B., Hlatywayo, J. D., Kianji, G. K., Marobhe, I., Mulowezi, A., Mutamina, D., Mwano, J. M., Shumba, B. and Tumwikirize, I.: Active fault mapping in Karonga-Malawi after the December 19, 2009 Ms 6.2 seismic event, J. African Earth Sci., 102, 233-246, doi:10.1016/j.jafrearsci.2014.10.010, 2015.

Marzocchi, W., Taroni, M. and Selva, J.: Accounting for epistemic uncertainty in PSHA: Logic tree and ensemble modeling,

960 Bull. Seismol. Soc. Am., 105(4), 2151-2159, doi:10.1785/0120140131, 2015.

McCalpin, J. P.: Paleoseismology, Academic press., 2009.

McGuire, R. K.: Probabilistic seismic hazard analysis and design earthquakes: closing the loop, Bull. - Seismol. Soc. Am., 85(5), 1275-1284, doi:10.1016/0148-9062(96)83355-9, 1995.

Middleton, T. A., Walker, R. T., Parsons, B., Lei, Q., Zhou, Y. and Ren, Z.: A major, intraplate, normal-faulting earthquake:

965 The 1739 Yinchuan event in northern China, J. Geophys. Res. Solid Earth, 121(1), 293-320, doi:10.1002/2015JB012355, 2016.

Mildon, Z. K., Toda, S., Faure Walker, J. P. and Roberts, G. P.: Evaluating models of Coulomb stress transfer: Is variable fault geometry important?, Geophys. Res. Lett., 43(24), 12,407-412,414, doi:10.1002/2016GL071128, 2016.

Molnar, P.: Earthquake recurrence intervals and plate tectonics, Bull. Seismol. Soc. Am., 69(1), 115-133, 1979.

970 Morell, K. D., Styron, R., Stirling, M., Griffin, J., Archuleta, R. and Onur, T.: Seismic Hazard Analyses From Geologic and Geomorphic Data: Current and Future Challenges, Tectonics, 39(10), e2018TC005365, doi:10.1029/2018TC005365, 2020.

Mortimer, E. J., Paton, D. A., Scholz, C. A. and Strecker, M. R.: Implications of structural inheritance in oblique rift zones for basin compartmentalization: Nkhata Basin, Malawi Rift (EARS), Mar. Pet. Geol., 72, 110-121, 
https://doi.org/10.5194/nhess-2021-306

Preprint. Discussion started: 16 November 2021

(c) Author(s) 2021. CC BY 4.0 License.

doi:10.1016/j.marpetgeo.2015.12.018, 2016.

Muirhead, J. D., Kattenhorn, S. A., Lee, H., Mana, S., Turrin, B. D., Fischer, T. P., Kianji, G., Dindi, E. and Stamps, D. S.: Evolution of upper crustal faulting assisted by magmatic volatile release during early-stage continental rift development in the East African Rift, Geosphere, 12(6), 1670-1700, doi:10.1130/GES01375.1, 2016.

Muirhead, J. D., Wright, L. J. M. and Scholz, C. A.: Rift evolution in regions of low magma input in East Africa, Earth Planet. Sci. Lett., 506, 332-346, doi:10.1016/j.eps1.2018.11.004, 2019.

980 Neely, J. S. and Stein, S.: Why do continental normal fault earthquakes have smaller maximum magnitudes?, Tectonophysics, 809(November 2020), 228854, doi:10.1016/j.tecto.2021.228854, 2021.

Ngoma, I., Kafodya, I., Kloukinas, P., Novelli, V., Macdonald, J. and Goda, K.: Building classification and seismic vulnerability of current housing construction in Malawi, Malawi J. Sci. Technol., 11(1), 57-72, 2019.

Nicol, A., Walsh, J., Berryman, K. and Villamor, P.: Interdependence of fault displacement rates and paleoearthquakes in an active rift, Geology, 34(10), 865-868, doi:10.1130/G22335.1, 2006.

Nicol, A., Van Dissen, R. J., Stirling, M. W. and Gerstenberger, M. C.: Completeness of the Paleoseismic Active-Fault Record in New Zealand, Seismol. Res. Lett., 87(6), 1299-1310, doi:10.1785/0220160088, 2016.

Njinju, E. A., Kolawole, F., Atekwana, E. A. E. A., Stamps, D. S., Atekwana, E. A. E. A., Abdelsalam, M. G. and Mickus, K. L.: Terrestrial heat flow in the Malawi Rifted Zone, East Africa: Implications for tectono-thermal inheritance in continental rift basins, J. Volcanol. Geotherm. Res., 387, doi:10.1016/j.jvolgeores.2019.07.023, 2019.

Novelli, V., Kloukinas, P., De Risi, R., Kafodya, I., Ngoma, I., Macdonald, J. and Goda, K.: Seismic Mitigation Framework for Non-engineered Masonry Buildings in Developing Countries: Application to Malawi in the East African Rift, in Resilient Structures and Infrastructure, pp. 195-223, Springer., 2019.

Nyblade, A. A. and Langston, C. A.: East African earthquakes below $20 \mathrm{~km}$ depth and their implications for crustal structure, Geophys. J. Int., 121(1), 49-62, doi:10.1111/j.1365-246X.1995.tb03510.x, 1995.

Olive, J. A., Behn, M. D. and Malatesta, L. C.: Modes of extensional faulting controlled by surface processes, Geophys. Res. Lett., 41(19), 6725-6733, doi:10.1002/2014GL061507, 2014.

Pace, B., Visini, F. and Peruzza, L.: FiSH : MATLAB Tools to Turn Fault Data into Seismic-Hazard Models, Seismol. Res. Lett., 87(2A), 374-386, doi:10.1785/0220150189, 2016.

1000 Pagani, M., Monelli, D., Weatherill, G., Danciu, L., Crowley, H., Silva, V., Henshaw, P., Butler, L., Nastasi, M., Panzeri, L., Simionato, M. and Vigano, D.: Openquake engine: An open hazard (and risk) software for the global earthquake model, Seismol. Res. Lett., 85(3), 692-702, doi:10.1785/0220130087, 2014.

Pagani, M., Garcia-Pelaez, J., Gee, R., Johnson, K., Poggi, V., Silva, V., Simionato, M., Styron, R., Viganò, D., Danciu, L., Monelli, D. and Weatherill, G.: The 2018 version of the Global Earthquake Model: Hazard component, Earthq. Spectra, 1005 36(1), 226-251, doi:10.1177/8755293020931866, 2020.

Peacock, D. C. P., Nixon, C. W., Rotevatn, A., Sanderson, D. J. and Zuluaga, L. F.: Glossary of fault and other fracture networks, J. Struct. Geol., 92, 12-29, doi:10.1016/j.jsg.2016.09.008, 2016. 
Perea, H., Masana, E. and Santanach, P.: A pragmatic approach to seismic parameters in a region with low seismicity: The case of Eastern Iberia, Nat. Hazards, 39(3), 451-477, doi:10.1007/s11069-006-0013-y, 2006.

Petersen, M. D., Zeng, Y., Haller, K. M., McCaffrey, R., Hammond, W. C., Bird, P., Moschetti, M., Shen, Z., Bormann, J. and Thatcher, W.: Geodesy- and geology-based slip-rate models for the Western United States (excluding California) national seismic hazard maps, U.S. Geol. Surv. Open-File Rep. 2013-1293, 86, doi:10.3133/ofr20131293, 2014.

Petit, C. and Ebinger, C.: Flexure and mechanical behavior of cratonic lithosphere: Gravity models of the East African and Baikal rifts, J. Geophys. Res. Solid Earth, doi:10.1029/2000JB900101, 2000.

1015 Plesch, A., Shaw, J. H., Benson, C., Bryant, W. A., Carena, S., Cooke, M., Dolan, J., Fuis, G., Gath, E., Grant, L., Hauksson, E., Jordan, T., Kamerling, M., Legg, M., Lindvall, S., Magistrale, H., Nicholson, C., Niemi, N., Oskin, M., Perry, S., Planansky, G., Rockwell, T., Shearer, P., Sorlien, C., Süss, M. P., Suppe, J., Treiman, J. and Yeats, R.: Community Fault Model (CFM) for southern California, Bull. Seismol. Soc. Am., 97(6), 1793-1802, doi:10.1785/0120050211, 2007.

Poggi, V., Durrheim, R., Tuluka, G. M., Weatherill, G., Gee, R., Pagani, M., Nyblade, A. and Delvaux, D.: Assessing seismic hazard of the East African Rift: a pilot study from GEM and AfricaArray, Bull. Earthq. Eng., 15(11), 4499-4529, doi:10.1007/s10518-017-0152-4, 2017.

Polonia, A., Gasperini, L., Amorosi, A., Bonatti, E., Bortoluzzi, G., Çagatay, N., Capotondi, L., Cormier, M. H., Gorur, N., McHugh, C. and Seeber, L.: Holocene slip rate of the North Anatolian Fault beneath the Sea of Marmara, Earth Planet. Sci. Lett., 227(3-4), 411-426, doi:10.1016/j.eps1.2004.07.042, 2004.

1025 Rhoades, D. A., Christophersen, A., Gerstenberger, M. C., Liukis, M., Silva, F., Marzocchi, W., Werner, M. J. and Jordan, T. H.: Highlights from the first ten years of the New Zealand earthquake forecast testing center, Seismol. Res. Lett., 89(4), 1229-1237, 2018.

Robertson, E. A. M., Biggs, J., Cashman, K. V, Floyd, M. A. and Vye-Brown, C.: Influence of regional tectonics and preexisting structures on the formation of elliptical calderas in the Kenyan Rift, in Geological Society Special Publication, vol. 420, pp. 43-67., 2016.

Sandwell, D., Mellors, R., Tong, X., Wei, M. and Wessel, P.: Open radar interferometry software for mapping surface Deformation, Eos, Trans. Am. Geophys. Union, doi:10.1029/2011EO280002, 2011.

Saria, E., Calais, E., Altamimi, Z., Willis, P. and Farah, H.: A new velocity field for Africa from combined GPS and DORIS space geodetic Solutions: Contribution to the definition of the African reference frame (AFREF), J. Geophys. Res. Solid Earth, 118(4), 1677-1697, doi:10.1002/jgrb.50137, 2013.

Scholz, C. A., Johnson, T. C., Cohen, A. S., King, J. W., Peck, J. A., Overpeck, J. T., Talbot, M. R., Brown, E. T., Kalindekafe, L., Amoako, P. Y. O., Lyons, R. P., Shanahan, T. M., Castañeda, I. S., Heil, C. W., Forman, S. L., McHargue, L. R., Beuning, K. R., Gomez, J. and Pierson, J.: East African megadroughts between 135 and 75 thousand years ago and bearing on early-modern human origins, Proc. Natl. Acad. Sci. U. S. A., 104(42), 16416-16421, 1040 doi:10.1073/pnas.0703874104, 2007.

Scholz, C. A., Shillington, D. J., Wright, L. J. M., Accardo, N., Gaherty, J. B. and Chindandali, P.: Intrarift fault fabric, 
segmentation, and basin evolution of the Lake Malawi (Nyasa) Rift, East Africa, Geosphere, 16(5), 1293-1311, doi:10.1130/GES02228.1, 2020.

Scholz, C. H. and Contreras, J. C.: Mechanics of continental rift architecture, Geology, 26(11), 967-970, doi:10.1130/00917613(1998)026<0967:MOCRA>2.3.CO, 1998.

Schwanghart, W. and Scherler, D.: Short Communication: TopoToolbox 2 - MATLAB-based software for topographic analysis and modeling in Earth surface sciences, Earth Surf. Dyn., 2(1), 1-7, doi:10.5194/esurf-2-1-2014, 2014.

Shaw, B. E.: Earthquake surface slip-length data is fit by constant stress drop and is useful for seismic hazard analysis, Bull. Seismol. Soc. Am., 103(2 A), 876-893, doi:10.1785/0120110258, 2013.

1050 Shaw, B. E. and Scholz, C. H.: Slip-length scaling in large earthquakes: Observations and theory and implications for earthquake physics, Geophys. Res. Lett., 28(15), 2995-2998, doi:10.1029/2000GL012762, 2001.

Shillington, D. J., Gaherty, J. B., Ebinger, C. J., Scholz, C. A., Selway, K., Nyblade, A. A., Bedrosian, P. A., Class, C., Nooner, S. L., Pritchard, M. E., Elliott, J., Chindandali, P. R. N., Mbogoni, G., Ferdinand, R. W., Boniface, N., Manya, S., Kamihanda, G., Saria, E., Mulibo, G., Salima, J., Mruma, A., Kalindekafe, L., Accardo, N. J., Ntambila, D., Kachingwe, M., 1055 Mesko, G. T., McCartney, T., Maquay, M., O’Donnell, J. P., Tepp, G., Mtelela, K., Trinhammer, P., Wood, D., Aaron, E., Gibaud, M., Rapa, M., Pfeifer, C., Mphepo, F., Gondwe, D., Arroyo, G., Eddy, C., Kamoga, B. and Moshi, M.: Acquisition of a unique onshore/offshore geophysical and geochemical dataset in the northern Malawi (Nyasa) rift, Seismol. Res. Lett., 87(6), 1406-1416, doi:10.1785/0220160112, 2016.

Shillington, D. J., Scholz, C. A., Chindandali, P. R. N., Gaherty, J. B., Accardo, N. J., Onyango, E., Ebinger, C. J. and 1060 Nyblade, A. A.: Controls on Rift Faulting in the North Basin of the Malawi (Nyasa) Rift, East Africa, Tectonics, 39(3), e2019TC005633, doi:10.1029/2019TC005633, 2020.

Shyu, J. B. H., Chuang, Y. R., Chen, Y. L., Lee, Y. R. and Cheng, C. T.: A new on-land seismogenic structure source database from the Taiwan earthquake model (TEM) project for seismic hazard analysis of Taiwan, Terr. Atmos. Ocean. Sci., 27(3), 311-323, doi:10.3319/TAO.2015.11.27.02(TEM), 2016.

1065 Stein, S., Geller, R. J. and Liu, M.: Why earthquake hazard maps often fail and what to do about it, Tectonophysics, 562563, 1-25, doi:10.1016/j.tecto.2012.06.047, 2012.

Stevens, V. L., Sloan, R. A., Chindandali, P. R., Wedmore, L. N. J., Salomon, G. W. and Muir, R. A.: The Entire Crust can be Seismogenic: Evidence from Southern Malawi, Tectonics, 40(6), e2020TC006654, doi:10.1029/2020tc006654, 2021.

Stirling, M., McVerry, G., Gerstenberger, M., Litchfield, N., Van Dissen, R., Berryman, K., Barnes, P., Wallace, L., 1070 Villamor, P., Langridge, R., Lamarche, G., Nodder, S., Reyners, M., Bradley, B., Rhoades, D., Smith, W., Nicol, A., Pettinga, J., Clark, K. and Jacobs, K.: National seismic hazard model for New Zealand: 2010 update, Bull. Seismol. Soc. Am., 102(4), 1514-1542, doi:10.1785/0120110170, 2012.

Stirling, M., Goded, T., Berryman, K. and Litchfield, N.: Selection of earthquake scaling relationships for seismic-hazard analysis, Bull. Seismol. Soc. Am., 103(6), 2993-3011, doi:10.1785/0120130052, 2013.

1075 Strader, A., Schneider, M. and Schorlemmer, D.: Prospective and retrospective evaluation of five-year earthquake forecast 
https://doi.org/10.5194/nhess-2021-306

Preprint. Discussion started: 16 November 2021

(c) Author(s) 2021. CC BY 4.0 License.

models for California, Geophys. J. Int., 211(1), 239-251, 2017.

Styron, R. and Pagani, M.: The GEM Global Active Faults Database, Earthq. Spectra, 36(1_suppl), 160-180, doi:10.1177/8755293020944182, 2020.

Styron, R., García-Pelaez, J. and Pagani, M.: CCAF-DB: The Caribbean and Central American active fault database, Nat.

Hazards Earth Syst. Sci., 20(3), 831-857, doi:10.5194/nhess-20-831-2020, 2020.

Sun, M., Gao, S. S., Liu, K. H., Mickus, K., Fu, X. and Yu, Y.: Receiver function investigation of crustal structure in the Malawi and Luangwa rift zones and adjacent areas, Gondwana Res., 89, 168-176, doi:10.1016/j.gr.2020.08.015, 2021.

Taroni, M., Marzocchi, W., Schorlemmer, D., Werner, M. J., Wiemer, S., Zechar, J. D., Heiniger, L. and Euchner, F.: Prospective CSEP evaluation of 1-day, 3-month, and 5-yr earthquake forecasts for Italy, Seismol. Res. Lett., 89(4), 12511085 1261, 2018.

Thingbaijam, K. K. S., Mai, P. M. and Goda, K.: New empirical earthquake source-scaling laws, Bull. Seismol. Soc. Am., 107(5), 2225-2246, doi:10.1785/0120170017, 2017.

Turcotte, D. L. and Schubert, G.: Geodynamics: Applications of continuum physics to geological problems, 450 pp, 1982. Valentini, A., DuRoss, C. B., Field, E. H., Gold, R. D., Briggs, R. W., Visini, F. and Pace, B.: Relaxing Segmentation on the 1090 Wasatch Fault Zone: Impact on Seismic Hazard, Bull. Seismol. Soc. Am., 110(1), 83-109, doi:10.1785/0120190088, 2020. Vallage, A. and Bollinger, L.: Testing Fault Models in Intraplate Settings: A Potential for Challenging the Seismic Hazard Assessment Inputs and Hypothesis?, Pure Appl. Geophys., 177(5), 1879-1889, doi:10.1007/s00024-019-02129-z, 2020.

Visini, F., Valentini, A., Chartier, T., Scotti, O. and Pace, B.: Computational Tools for Relaxing the Fault Segmentation in Probabilistic Seismic Hazard Modelling in Complex Fault Systems, Pure Appl. Geophys., 177(5), 1855-1877, 1095 doi:10.1007/s00024-019-02114-6, 2020.

Vittori, E., Delvaux, D. and Kervyn, F.: Kanda fault: A major seismogenic element west of the Rukwa Rift (Tanzania, East Africa), J. Geodyn., 24(1-4), 139-153, doi:10.1016/S0264-3707(96)00038-5, 1997.

Wallace, L. M., Barnes, P., Beavan, J., Van Dissen, R., Litchfield, N., Mountjoy, J., Langridge, R., Lamarche, G. and Pondard, N.: The kinematics of a transition from subduction to strike-slip: An example from the central New Zealand plate 1100 boundary, J. Geophys. Res. Solid Earth, 117(2), doi:10.1029/2011JB008640, 2012.

Wallace, R. E.: Earthquake recurrence intervals on the San Andreas fault, Bull. Geol. Soc. Am., 81(10), 2875-2890, doi:10.1130/0016-7606(1970)81[2875:ERIOTS]2.0.CO;2, 1970.

Walshaw, R. D.: The Geology of the Nchue-Balaka Area, Bull. Geol. Surv. Malawi, 19, 1965.

Walter, J.: The Geology of the Salima-Mvera Mission Area, Bull. Geol. Surv. Malawi, 30, 1972.

1105 Walters, R. J., Gregory, L. C., Wedmore, L. N. J., Craig, T. J., McCaffrey, K., Wilkinson, M., Chen, J., Li, Z., Elliott, J. R., Goodall, H., Iezzi, F., Livio, F., Michetti, A. M., Roberts, G. and Vittori, E.: Dual control of fault intersections on stop-start rupture in the 2016 Central Italy seismic sequence, Earth Planet. Sci. Lett., 500, 1-14, doi:10.1016/j.epsl.2018.07.043, 2018. Wang, T., Feng, J., Liu, K. H. and Gao, S. S.: Crustal structure beneath the Malawi and Luangwa Rift Zones and adjacent areas from ambient noise tomography, Gondwana Res., 67, 187-198, doi:10.1016/j.gr.2018.10.018, 2019. 
1110 Wedmore, L. N. J., Faure Walker, J. P., Roberts, G. P., Sammonds, P. R., McCaffrey, K. J. W. and Cowie, P. A.: A 667 year record of coseismic and interseismic Coulomb stress changes in central Italy reveals the role of fault interaction in controlling irregular earthquake recurrence intervals, J. Geophys. Res. Solid Earth, 122(7), 5691-5711, doi:10.1002/2017JB014054, 2017.

Wedmore, L. N. J., Biggs, J., Williams, J. N., Fagereng, Dulanya, Z., Mphepo, F. and Mdala, H.: Active Fault Scarps in

1115 Southern Malawi and Their Implications for the Distribution of Strain in Incipient Continental Rifts, Tectonics, 39(3), e2019TC005834, doi:10.1029/2019TC005834, 2020a.

Wedmore, L. N. J., Williams, J. N., Biggs, J., Fagereng, Å., Mphepo, F., Dulanya, Z., Willoughby, J., Mdala, H. and Adams, B. A.: Structural inheritance and border fault reactivation during active early-stage rifting along the Thyolo fault, Malawi, J. Struct. Geol., 139, 104097, doi:10.1016/j.jsg.2020.104097, 2020 b.

1120 Wedmore, L. N. J., Biggs, J., Floyd, M., Fagereng, Mdala, H., Chindandali, P., Williams, J. N. and Mphepo, F.: Geodetic Constraints on Cratonic Microplates and Broad Strain During Rifting of Thick Southern African Lithosphere, Geophys. Res. Lett., 48(17), doi:10.1029/2021GL093785, 2021.

Weldon, R., Scharer, K., Fumal, T. and Biasi, G.: Wrightwood and the earthquake cycle: What a long recurrence record tells us about how faults work, GSA Today, 14(9), 4-10, doi:10.1130/1052-5173(2004)014<4:WATECW>2.0CO;2, 2004.

1125 Wells, D. L. and Coppersmith, K. J.: New Empirical Relationships among Magnitude, Rupture Length, Rupture Width, Rupture Area, and Surface Displacement, Bull. Seismol. Soc. Am., 84(4), 974-1002, doi:<p></p>, 1994.

Wesnousky, S. G.: Displacement and geometrical characteristics of earthquake surface ruptures: Issues and implications for seismic-hazard analysis and the process of earthquake rupture, Bull. Seismol. Soc. Am., 98(4), 1609-1632, doi:10.1785/0120070111, 2008.

1130 Wheeler, W. H. and Rosendahl, B. R.: Geometry of the Livingstone Mountains Border Fault, Nyasa (Malawi) Rift, East Africa, Tectonics, 13(2), 303-312, doi:10.1029/93TC02314, 1994.

Widess, M. B.: How Thin Is a Thin Bed?, Geophysics, 38(6), 1176-1180, doi:10.1190/1.1440403, 1973.

Williams, J., Wedmore, L., Scholz, C. A., Kolawole, F., Wright, L. J. M., Shillington, D. J., Fagereng, Å., Biggs, J., Mdala, H., Dulanya, Z., Mphepo, F., Chindandali, P. and Werner, M. J.: Malawi Active Fault Database, , 1135 doi:10.5281/ZENODO.5507190, 2021a.

Williams, J. N., Fagereng, Å., Wedmore, L. N. J., Biggs, J., Mphepo, F., Dulanya, Z., Mdala, H. and Blenkinsop, T.: How Do Variably Striking Faults Reactivate During Rifting? Insights From Southern Malawi, Geochemistry, Geophys. Geosystems, 20(7), 3588-3607, doi:10.1029/2019GC008219, 2019.

Williams, J. N., Mdala, H., Fagereng, Å., Wedmore, L. N. J., Biggs, J., Dulany, Z., Chindandali, P. and Mphepo, F.: A 1140 systems-based approach to parameterise seismic hazard in regions with little historical or instrumental seismicity: Active fault and seismogenic source databases for southern Malawi, Solid Earth, 12(1), 187-217, doi:10.5194/se-12-187-2021, $2021 b$.

Williams, J. N., Wedmore, L. N. J., Scholz, C. A., Kolawole, F., Wright, L. J. M., Shillington, D. J., Fagereng, A., Biggs, J., 
Mdala, H., Dulanya, Z. and Werner, M. J.: The Malawi Active Fault Database: an onshore-offshore database for regional assessment of seismic hazard and tectonic evolution, Earth Sp. Sci. Open Arch. ESSOAr, 2021c.

Wright, L. J. M., Muirhead, J. D. and Scholz, C. A.: Spatiotemporal Variations in Upper Crustal Extension Across the Different Basement Terranes of the Lake Tanganyika Rift, East Africa, Tectonics, 39(3), doi:10.1029/2019TC006019, 2020. Xu, Y., He, H., Deng, Q., Allen, M. B., Sun, H. and Bi, L.: The CE 1303 Hongdong Earthquake and the Huoshan Piedmont Fault, Shanxi Graben: Implications for Magnitude Limits of Normal Fault Earthquakes, J. Geophys. Res. Solid Earth, 1150 123(4), 3098-3121, doi:10.1002/2017JB014928, 2018.

Yang, Z. and Chen, W. P.: Earthquakes along the East African Rift System: A multiscale, system-wide perspective, J. Geophys. Res. Solid Earth, 115(12), doi:10.1029/2009JB006779, 2010.

Youngs, R. R. and Coppersmith, K. J.: Implications of fault slip rates and earthquake recurrence models to probabilistic seismic hazard estimates, Bull. Seismol. Soc. Am., 75(4), 939-964, 1985.

1155 Zechar, J. D. and Frankel, K. L.: Incorporating and reporting uncertainties in fault slip rates, J. Geophys. Res. Solid Earth, 114(12), 1-9, doi:10.1029/2009JB006325, 2009.

Zechar, J. D., Schorlemmer, D., Werner, M. J., Gerstenberger, M. C., Rhoades, D. A. and Jordan, T. H.: Regional earthquake likelihood models I: First-order results, Bull. Seismol. Soc. Am., 103(2A), 787-798, 2013.

Zeng, Y. and Shen, Z. K.: Fault network modeling of crustal deformation in California constrained using GPS and geologic observations, Tectonophysics, 612-613, 1-17, doi:10.1016/j.tecto.2013.11.030, 2014.

Zheng, W., Oliva, S. J., Ebinger, C. and Pritchard, M. E.: Aseismic Deformation During the 2014 Mw 5.2 Karonga Earthquake, Malawi, From Satellite Interferometry and Earthquake Source Mechanisms, Geophys. Res. Lett., 47(22), doi:10.1029/2020GL090930, 2020. 